\title{
Thallium elemental and isotopic systematics in ocean island lavas
}

2

3

4

5

6

$7 \quad{ }^{3}$ School of Environment, Earth and Ecosystem Sciences, The Open University, Milton Keynes, UK

$8 \quad{ }^{4}$ Université de Paris, Institut de Physique du Globe de Paris, CNRS, F-75005 Paris, France

$9 \quad{ }^{5}$ ISTerre, Université Grenoble Alpes, CNRS, Grenoble, France

$10{ }^{6}$ Institut für Mineralogie, Westfälische Wilhelms-Universität Münster, Corrensstraße 24, 48149 Münster,

11 Germany

$12{ }^{7}$ Abteilung Isotopengeologie, Universität Göttingen, Goldschmidtstraße 1, 37077 Göttingen, Germany

13

14

15 Abstract word count: 340

16 Main text word count: 7843

17 Figures: 9

18 Tables: 6

19 Supplementary Materials: Appendix (683 words), 6 figures, 1 data annex (3 tables)

20 Keywords: thallium, stable isotopes, mantle heterogeneity, ocean island basalts 


\section{Abstract}

The Earth's mantle exhibits marked chemical heterogeneity, sampled via oceanic basalts. We provide a comprehensive examination of thallium systematics in ocean island basalts $(\mathrm{OIB})$ : new high-precision trace element analyses, including $\mathrm{Tl}$, and $\mathrm{Tl}$ isotopic compositions for $48 \mathrm{OIB}$ spanning the entire range of observed $\mathrm{Sr}-\mathrm{Nd}-\mathrm{Hf}-\mathrm{Pb}$ isotope ratios. All investigated OIB are characterised by ubiquitous Tl depletion requiring $\mathrm{OIB}$ mantle sources to have $\mathrm{Tl}$ concentrations as low as $0.2 \mathrm{ng} / \mathrm{g}$, which is an order of magnitude lower than estimates for the primitive mantle and similar to $\mathrm{Tl}$ concentrations inferred for the depleted mantle. The low $\mathrm{Tl}$ concentrations inferred for OIB mantle sources are interpreted to reflect near quantitative removal of $\mathrm{Tl}$ during subduction and inefficient $\mathrm{Tl}$ recycling into the deeper mantle. If true, the $\mathrm{Tl}$ isotopic composition of surface materials may not be readily translated to the mantle sources of OIB.

The new OIB dataset shows a $>10 \varepsilon$-unit range in primary isotopic variation, from $\varepsilon^{205} \mathrm{Tl}=-6.4$ to +6.6 . However, the majority of samples (32 of 48) are within uncertainty of mantle values $\left(\varepsilon^{205} \mathrm{Tl}=-2 \pm 1\right)$, and show no co-variation with radiogenic isotopic composition. Notably, OIB with only minor Tl depletion (11 samples) have $\mathrm{Tl}$ isotopic compositions outside the mantle range. The $\mathrm{Tl}$ concentration contrast between the mantle and inputs such as sediments and altered basalt is so great that minor additions $(<1 \%$ by mass $)$ of high-Tl material will dominate the isotopic budget of a lava, with decoupling of $\mathrm{Tl}$ and radiogenic isotopic compositions as an expected result. Thallium isotopic compositions of OIB are therefore difficult to link directly to radiogenic isotope variations and the mantle components they may reflect. Indeed, if isotopically distinct $\mathrm{Tl}$ from altered oceanic crust and/or sediments were efficiently recycled into the mantle and sampled via $\mathrm{OIB}$, more variation in the $\mathrm{Tl}$ isotopic composition of OIB would be expected than is observed. The markedly unsystematic primary $\mathrm{Tl}$ isotopic variations in $\mathrm{OIB}$ therefore likely reflect the residual $\mathrm{Tl}$ isotopic composition of subducted material, and/or Tl acquired en route to the surface via shallow-level crustal assimilation.

\section{Introduction}

The majority of intraplate oceanic volcanism is the surface expression of deep-rooted thermochemical upwellings, or 'mantle plumes' (e.g. Morgan, 1971; Hofmann and White, 1982; Montelli et al., 2006). Ocean island basalts (OIB) thus provide a window into geochemical heterogeneity of the otherwise inaccessible deep mantle (e.g. White, 2015). Zindler and Hart (1986) first proposed a classification scheme for oceanic 
basalts based on the observation that their radiogenic $\mathrm{Sr}-\mathrm{Nd}-\mathrm{Pb}$ isotope ratios vary systematically between a restricted number of isotopic signatures, termed 'end-members' or 'components'. Decades of subsequent work has subdivided or refined the details and interpretations of the radiogenic $\mathrm{Sr}-\mathrm{Nd}-\mathrm{Pb}$ isotopic variability in oceanic basalts (e.g. Weaver, 1991; Chauvel et al., 1992; Hofmann, 1997; Workman and Hart, 2005; Willbold and Stracke, 2006). In general, the chemical variations observed in OIB can be reproduced via mixing of ambient mantle with other components, commonly identified with various recycled crustal lithologies (e.g. Hofmann and White, 1982; Weaver, 1991; Chauvel et al., 1992). Within this framework, it is suggested that the so-called HIMU (high $\mu={ }^{238} \mathrm{U} /{ }^{204} \mathrm{~Pb}$ ) signature may represent ancient subducted oceanic crust, isolated for $\sim 2 \mathrm{Ga}$, while enriched mantle (EM)-type signatures might represent incorporation of heterogeneous continental components in the form of clastic sediments or continental crust eroded at destructive plate margins (e.g. Hofmann and White, 1982; Zindler and Hart, 1986; Chauvel et al., 1992; Hofmann, 1997; Stracke et al., 2003, 2005; Willbold and Stracke 2006, 2010; Stracke, 2012).

Inferring mantle source compositions from the radiogenic isotope ratios observed in basalts is challenging, because sampling of the different source components via partial melting depends on a number of factors, such as initial concentrations, melting behaviour, partition coefficients, extent of melt mixing, and time elapsed between parent-daughter fractionation events. As a consequence, it is often difficult to reach unambiguous interpretations of the origins and history of mantle sources.

Resolving such ambiguities about the nature and origin of mantle composition and evolution on the basis of radiogenic isotopic variation observed in OIB is necessary to constrain global geochemical cycles and the Earth's thermal evolution. Stable isotope systematics may provide useful independent constraints, as lowtemperature surface environments have the potential to generate resolvable stable isotope fractionations, which might then be traced through subduction recycling into the mantle and subsequently sampled via OIB. Analytical advances have enabled the development and application of a variety of stable isotope systems to igneous rocks, motivated in part by the potential for such systems to act as a tracer of recycled materials. Many of these advances were recently reviewed in Teng et al. (eds), (2017), for stable isotope systems from Li to U. In general, larger isotope fractionations occur in surface environments than magmatic environments, and so a logical aim is to identify the incorporation of recycled surface material by determining whether 
Thallium is a highly incompatible element, conventionally grouped with the alkali elements due to the similar ionic radii of $\mathrm{Tl}^{+}$and the heavier alkali metals (e.g. Shaw, 1952; Heinrichs et al., 1980). The relative abundance of the two stable isotopes, ${ }^{205} \mathrm{Tl}(\sim 70 \%)$ and ${ }^{203} \mathrm{Tl}(\sim 30 \%)$, is reported as $\varepsilon^{205} \mathrm{Tl}$ relative to the NIST SRM 997 Tl isotope standard (Rehkämper and Halliday, 1999):

$$
\left.\varepsilon^{205} \mathrm{TI}_{\text {SRM997 }}=10000 \cdot\left[{ }^{205} \mathrm{TI} /{ }^{203} \mathrm{~T} I_{\text {sample }}-{ }^{205} \mathrm{TI} /{ }^{203} \mathrm{~T} \mathrm{I}_{\text {SRM997 }}\right) /\left({ }^{205} \mathrm{TI} /{ }^{203} \mathrm{~T} \mathrm{I}_{\text {SRM997 }}\right)\right]
$$

Thallium does not appear to undergo isotope fractionation during the high-temperature igneous processes of partial melting, metasomatism, and anhydrous fractional crystallisation. A systematic study of two co-genetic igneous suites spanning a range of $\mathrm{SiO}_{2}$ contents from Iceland and the Mariana island arc found a restricted range in $\varepsilon^{205} \mathrm{Tl}$ (Hekla: $\varepsilon^{205} \mathrm{Tl}$ from -2.2 to -0.7; Anatahan: $\varepsilon^{205} \mathrm{Tl}$ from -2.9 to 0.0 ), and indicates that no analytically resolvable $\mathrm{Tl}$ isotope fractionation occurs during anhydrous magmatic differentiation (Prytulak et al., 2017). Fitzpayne et al. (2020) analysed phlogopite mineral separates from highly metasomatised mantle xenoliths, again finding a strikingly restricted range in isotopic composition $\left(\varepsilon^{205} \mathrm{Tl}=-2.5 \pm 1.32 \mathrm{sd}, \mathrm{n}\right.$ $=25$ ). This implies that the $\mathrm{Tl}$ isotopic composition of magmatic products should correspond to that of their sources, allowing the use of $\mathrm{Tl}$ isotope ratios to disambiguate the history of even evolved igneous rocks.

Direct measurements of $\mathrm{Tl}$ isotope ratios in mantle peridotites are hindered by their low concentrations (e.g. primitive mantle <4 ng/g: McDonough and Sun, 1995; 4.1 ng/g: Palme and O’Neill, 2014). However, a harzburgite analysed by Nielsen et al. (2015) with $\varepsilon^{205} \mathrm{Tl}=-2.0 \pm 0.8(2 \mathrm{sd})$, is indistinguishable from the $\mathrm{Tl}$ isotopic composition of MORB $\left(\varepsilon^{205} \mathrm{Tl}=-2.0 \pm 1.0\right.$ 2sd; Nielsen et al., 2006a, 2017b), thus suggesting that $\mathrm{Tl}$ isotopes are not fractionated by partial melting processes.

Thallium elemental systematics in MORB are constrained by several large self-consistent (i.e. samples measured by the same protocols in the same laboratory) datasets collected in recent years, including wellcalibrated high-precision Tl concentrations (Jenner and O'Neill, 2012; Nielsen et al., 2014; Yang et al., 2018).

Thallium concentrations are generally $100 \mathrm{~s}$ to $10,000 \mathrm{~s}$ of $\mathrm{ng} / \mathrm{g}$ with large isotopic fractionations at the Earth's surface. The continental crust is the main terrestrial host of Tl ( $\sim 500 \mathrm{ng} / \mathrm{g}$ e.g. Rudnick and Gao, 2003; Jenner, 2017), with a Tl isotopic composition, inferred via loess, indistinguishable from MORB 
(Nielsen et al. 2006b). Relative to the mantle, modern altered upper oceanic crust (AOC) has elevated Tl concentrations ( $200 \mathrm{ng} / \mathrm{g}$ ) and light $\mathrm{Tl}$ isotopic compositions $\left(\varepsilon^{205} \mathrm{Tl} \sim-20\right.$ to -5 ; Nielsen et al., 2006b, 2017b), whereas FeMn sediments have very high Tl contents (>10,000 ng/g) and preferentially incorporate the heavier $\mathrm{Tl}$ isotope $\left(\varepsilon^{205} \mathrm{Tl} \sim+5\right.$ to +15 ; review of Nielsen et al., 2017b). The $\mathrm{Tl}$ concentration contrast spanning order of magnitude between the mantle and potential recycled components, coupled with the resolvable and opposite directions of isotope fractionation in surface materials relative to the mantle, theoretically makes $\mathrm{Tl}$ isotopic compositions extremely sensitive to contributions of recycled surface materials to the mantle. Indeed, previous work investigating subduction settings has shown that $\mathrm{Tl}$ isotope ratios of arc lavas can be directly linked to the isotopic composition of materials subducting outboard of the associated trenches (Prytulak et al., 2013; Nielsen et al., 2015, 2016, 2017a; Shu et al., 2017, 2019). By the same reasoning, $\mathrm{Tl}$ isotopic compositions may covary with traditional radiogenic isotope ratios in ocean island basalts, used to define mantle components. If some EM-type signatures reflect incorporation of recycled sediments, then isotopically heavy $\mathrm{Tl}$ is predicted. Likewise, if the HIMU OIB signature develops via input of AOC then HIMU lavas would be expected to exhibit isotopically light $\mathrm{Tl}$.

\subsection{Sample selection and aims}

Previous $\mathrm{Tl}$ isotope studies of OIB have used the interpretive framework of isotopically heavy thallium indicating FeMn sediments and/or pelagic clays, and isotopically light thallium indicating AOC. Previous work has examined Hawai'i (Nielsen et al., 2006a), the Azores (Nielsen et al., 2007), Iceland (Nielsen et al., 2007; Prytulak et al., 2017), and St. Helena (Blusztajn et al., 2018), documenting a range of $\varepsilon^{205} \mathrm{Tl}=-10$ to +3.9. This large range is mostly due to variations in rocks from Hawai ${ }^{\circ} \mathrm{i}$, ascribed to the addition of FeMn sediments, and St Helena, ascribed to the addition of AOC. Thus far, no published studies have examined EM-type lavas, or HIMU lavas from localities other than St Helena. Here, we investigate EM-type lavas and expand the number of HIMU localities, to better characterize the full range of known OIB sources. All selected samples have radiogenic isotope data and show limited evidence of alteration (e.g. low loss on ignition, freshness on inspection of thin section). The 48 new analyses comprise 32 EM-type (13 'EMI', 19 other EM) and 16 HIMU lavas (Table 1). We aim to evaluate, on a global scale, the potential relationships between $\mathrm{Tl}$ elemental abundances, $\mathrm{Tl}$ stable isotopes, and radiogenic isotopic compositions in $\mathrm{OIB}$ to investigate the nature of mantle components and the efficiency of $\mathrm{Tl}$ cycling between crust and mantle. 


\section{Methods}

Sample digestions and chemical separations were carried out in the MAGIC Laboratories, Imperial College London, as described in Brett et al. (2018). Purified water (resistivity $18.2 \mathrm{M} \Omega \mathrm{cm}$ from a Milli-Q system) and acids purified via sub-boiling distillation in quartz or PTFE stills were used throughout.

\subsection{Trace element determination}

While $\mathrm{Tl}$ concentrations can be determined during isotope ratio measurements, early studies report uncertainties of $25 \%$ (e.g. Rehkämper et al., 2002), improved to $~ 10 \%$ by later work (e.g. Prytulak et al. 2013) for relatively high concentration samples $>20 \mathrm{ng} / \mathrm{g}$. In contrast, the precision of $\mathrm{Tl}$ measurements via ICP-QQQ ('triple-quad' inductively coupled plasma mass spectrometer) is generally $<4 \% \mathrm{RSD}$, though the uncertainty is higher for samples with lower Tl concentrations. Concentrations for 39 trace elements, including Tl, were obtained at the Open University, UK, using an Agilent 8800 ICP-QQQ following the procedure detailed in Brett et al. (2018).

In brief, for most samples approximately $50 \mathrm{mg}$ of powder was weighed into a screw-top Savillex ${ }^{\circledR}$ PFA vial. To ensure precise and accurate determination of low $\mathrm{Tl}$ concentrations, $\sim 75-100 \mathrm{mg}$ of powder was weighed out for samples G6, FH-01, TH39, HV64, 74-386, and 108B. A 3:1 mixture of concentrated $\mathrm{HF}$ and $\mathrm{HNO}_{3}$ was added to the vials, which were then heated to $140{ }^{\circ} \mathrm{C}$ for at least 24 hours. Samples were subsequently evaporated to near dryness, and dried down from $0.5-1 \mathrm{ml}$ concentrated $\mathrm{HNO}_{3}$ at $180{ }^{\circ} \mathrm{C}$ at least three times in order to destroy insoluble fluorides formed during the initial digestion. Samples were next taken up in 2 $\mathrm{ml} 6 \mathrm{M} \mathrm{HCl}$, and refluxed at $120{ }^{\circ} \mathrm{C}$ for at least 24 hours, during which time they were ultrasonicated twice for 20 minutes, before being evaporated to complete dryness at $120^{\circ} \mathrm{C} .2 \mathrm{ml}$ concentrated $\mathrm{HNO}_{3}$ and $1 \mathrm{ml}$ water were then added to each sample, followed by refluxing at $140{ }^{\circ} \mathrm{C}$ for at least 24 hours. Samples were again evaporated to dryness at $140{ }^{\circ} \mathrm{C}$, before finally being made up to 1000 -fold dilution in $2 \% \mathrm{HNO}_{3}$.

Sample solutions were aspirated using a quartz microflow nebuliser with an uptake rate of $0.5 \mathrm{ml} \mathrm{min}^{-1}$, with sensitivity on the order of $1-5 \times 10^{7}$ cps per $\mu \mathrm{g} / \mathrm{ml}$, depending on the element. Two collision/reaction gas configurations were used: no gas, for $\mathrm{Tl}$ and most other elements, and $\mathrm{O}_{2}$, for most Rare Earth Elements (see Brett et al., 2018). In the no gas configuration, oxide levels, measured as $\mathrm{CeO}^{+} / \mathrm{Ce}^{+}$, were kept below $1 \%$; double-charged species, measured as $\mathrm{Ce}^{2+} / \mathrm{Ce}^{+}$, were kept at $1.6 \%$. 
All elements except $\mathrm{Tl}$ were calibrated using the values provided in Eggins et al. (1997) for USGS reference materials (RMs) W-2 and DNC-1. For Tl, USGS RMs BIR-1, BHVO-2 and AGV-1 were used as calibrators, employing the values of Brett et al. (2018). Calibrator materials were run at the beginning of each measurement session. An internal solution standard (with $\mathrm{Be}, \mathrm{Rh}, \mathrm{In}, \mathrm{Tm}, \mathrm{Re}, \mathrm{Bi}$ ) was added online to monitor and correct instrumental drift. Drift was further monitored after every five measurements of unknown solutions with a measurement block comprising GSJ RM JB-2, $2 \% \mathrm{HNO}_{3}$, and a repeated unknown sample (G-6).

\subsection{Thallium isotope ratio determination}

Procedures for $\mathrm{Tl}$ separation and subsequent measurement of $\mathrm{Tl}$ isotopic compositions followed established protocols. Briefly, all procedures were carried out at the MAGIC Laboratories, Imperial College London. Samples were digested via standard $\mathrm{HF}-\mathrm{HNO}_{3}$ techniques, and $\mathrm{Tl}$ isolated from the matrix using a 2-stage ion exchange chromatography procedure detailed in Rehkämper and Halliday (1999) and Nielsen et al. (2004), with modifications as described in Brett et al. (2018). The majority of isotope ratio measurements were performed using a $N u$ HR MC-ICP-MS equipped with $10^{11} \Omega$ resistors, as low resolution measurements using a $\sim 100 \mu \mathrm{l} / \mathrm{min}$ flow rate nebuliser connected to an Aridus, Aridus II or $N u D S N$ desolvating system, with $\mathrm{Tl}$ solutions ranging in concentration from $2-5 \mathrm{ng} \mathrm{ml}^{-1}$ and a sensitivity of $\sim 800 \mathrm{~V} / \mathrm{ppm} \mathrm{Tl}$.

The limited availability of powder for some OIB samples, coupled with low Tl concentrations, required measurement of solutions with $\mathrm{Tl}$ concentrations of $<1 \mathrm{ng} / \mathrm{ml}$. Measurements of these low-concentration analytes on the $N u H R M C-I C P-M S$ are less precise than those of solutions with $2-5 \mathrm{ng} / \mathrm{ml} \mathrm{Tl}$. Measurements on a Nu Plasma II MC-ICP-MS during the later phase of the project have significantly increased sensitivity compared to the $N u$ HR MC-ICP-MS. For Tl, sensitivity on the Nu Plasma II was routinely well in excess of $1000 \mathrm{~V} / \mathrm{ppm}$ at the same measurement conditions. Otherwise, the method for isotope ratio determination on the Nu Plasma II was identical to the Nu HR, as described in Brett et al. (2018).

A secondary $\mathrm{Tl}$ isotope reference solution from Aldrich ('Aldrich $\mathrm{Tl}$ solution'), first characterised by Rehkämper and Halliday (1999), is routinely used (>2000 measurements across at least seven laboratories; Nielsen et al., 2017b) to monitor machine performance. At least two measurements of the Aldrich Tl solution were performed at the beginning and end of each session, with additional measurements performed 
throughout, typically after every 6 unknown samples. Additionally, a well-characterised USGS reference material (typically BCR-2, though AGV-2 and BHVO-2 were also used) was processed through the complete sample preparation procedure with every batch of 10 samples prepared for MC-ICP-MS analysis.

Powder leaching tests. Thallium can be concentrated in secondary clays and ferromanganese coatings. To assess possible effects of secondary, low-temperature alteration processes on $\mathrm{Tl}$ isotopic composition, powder leaching experiments were performed. Samples with isotopic compositions that differed from average MORB by more than $3 \varepsilon$ units, as determined on unleached powders, were chosen for these leaching experiments.

The leaching protocol followed the cold acid leaching of Weis and Frey (1991). Approximately $10 \mathrm{ml}$ 6M $\mathrm{HCl}$ was added to $100-300 \mathrm{mg}$ of a sample powder, and the suspension was ultrasonicated for 30 minutes. After settling for at least 30 minutes, the leachate was drawn off and discarded, and a further $\sim 10 \mathrm{ml} 6 \mathrm{M} \mathrm{HCl}$ was added to samples, which were then ultrasonicated again for 20-30 minutes. This process was repeated until the leachate ran clear (a minimum of 3 cycles), and was then repeated a further 2 times with purified water in place of $\mathrm{HCl}$. Leached powders were then evaporated, digested, separated and measured in the same manner as unleached powders.

\section{Results}

\subsection{Trace element concentrations}

Table 2 lists key major and trace element concentrations for the 48 OIB samples. Thallium concentrations range from 7 to $235 \mathrm{ng} / \mathrm{g}$. The full dataset of 39 elements is provided in Electronic Annex 1 along with results for the reference materials measured contemporaneously with the OIB samples. Trace element concentrations obtained for repeated measurement of BCR-2 and JB-2 are in good agreement with accepted values (Electronic Annex 2). For most elements, RSDs are generally <3\%; for Tl, RSDs are <7\% for 34 samples, and $>10 \%$ for 5 samples (Electronic Annex 2).

Many samples have existing trace element data published on the same powders (Electronic Annex 2,3), and there is generally good agreement with previous work. We emphasize that the new data pays particular attention to the calibration of $\mathrm{Tl}$ concentration measurements, and is therefore be used throughout the remainder of this work. 


\subsection{Thallium isotope ratios}

Table 2 presents the $\mathrm{Tl}$ isotopic composition of the 48 global OIB measured in this study, highlighting samples with isotopic compositions determined for both leached and unleached powders. Thallium isotopic compositions range from -6.4 to +6.6 and do not co-vary with Tl concentrations (Fig. 1). The quoted uncertainties take into account the measurement instrument and signal intensity, and are reported as the highest of (1) the uncertainty for repeat analyses of BCR-2 on the $N u H R$, (2) the uncertainty for repeated measurements of the Aldrich Tl solution on the Nu Plasma II, or (3) the uncertainty for repeat analyses of a given sample.

The long-term intermediate precision of the Aldrich $\mathrm{Tl}$ solution measured on the $\mathrm{Nu} H R$ contemporaneously with OIB samples was $\varepsilon^{205} \mathrm{Tl}=-0.8 \pm 0.4(2 \mathrm{sd} ; \mathrm{n}=211,14$ sessions, 4 years $)$, calculated using the average $\varepsilon^{205} \mathrm{Tl}$ values obtained during each measurement session due to the large number of analyses. Unleached digestions of USGS reference materials AGV-2 (1), BCR-2 (10) and BHVO-2 (2) yielded $\varepsilon^{205} \mathrm{Tl}$ values of $2.9 \pm 0.5(2 \mathrm{sd} ; \mathrm{n}=3,1$ session $),-2.6 \pm 0.5(2 \mathrm{sd} ; \mathrm{n}=21,4$ sessions $)$, and $-1.2 \pm 0.8(2 \mathrm{sd} ; \mathrm{n}=3,1$ session $)$ for measurements with signal intensity on mass $205>1$ V. For measurements of BCR-2 (4 digestions) with signal intensity $<1 \mathrm{~V}, \varepsilon^{205} \mathrm{Tl}=-2.5 \pm 1.3(2 \mathrm{sd} ; \mathrm{n}=21,3$ sessions $)$. For both Aldrich solution and USGS RMs, many of these determinations were first reported in Brett et al. (2018) and the values obtained are in good agreement with previous compilations (Nielsen et al., 2017b; Prytulak et al., 2017).

The average obtained for the Aldrich Tl solution on the $N u$ Plasma II was $\varepsilon^{205} \mathrm{Tl}=-0.8 \pm 0.8(2 \mathrm{sd} ; \mathrm{n}=28,2$ sessions, 2 months), with the higher uncertainty reflecting both the smaller number of analyses and the lower concentration of solutions. One unleached dissolution of BCR-2 yielded $\varepsilon^{205} \mathrm{Tl}=-3.1 \pm 0.8(2 \mathrm{sd} ; \mathrm{n}=1)$, while one leached dissolution yielded $\varepsilon^{205} \mathrm{Tl}=-2.1 \pm 0.8(2 \mathrm{sd}, \mathrm{n}=1)$, demonstrating that our leaching procedure does not introduce resolvable $\varepsilon^{205} \mathrm{Tl}$ fractionations.

\subsection{Assessing secondary effects on $\mathrm{Tl}$ isotope ratios}

Melt evolution. Many stable isotope systems display isotope fractionation during fractional crystallisation (e.g. Teng et al., 2017). Thallium behaviour has been previously been investigated using two cogenetic suites with invariant radiogenic isotopic compositions from different tectonic settings: Hekla, Iceland, and Anatahan, Marianas (Prytulak et al., 2017). Neither suite fractionates hydrous phases, nor do they exhibit 
resolvable $\mathrm{Tl}$ isotope fractionation during differentiation. Rader et al. (2018) show that hydrous K-rich phases such as micas can exhibit distinct $\mathrm{Tl}$ isotopic compositions $\left(\varepsilon^{205} \mathrm{Tl}\right.$ from -12.1 to +5.3$)$ coupled with significant Tl enrichments ( $>5 \mu \mathrm{g} / \mathrm{g}$ ). As such, while it is not possible to completely rule out crystallisationinduced fractionation, it is highly unlikely for the OIB studied here. With the caveat that our samples are not genetically related, there is no systematic variation of $\varepsilon^{205} \mathrm{Tl}$ with inferred or observed phenocryst phases or with $\mathrm{MgO}$ content in the current dataset (Fig. S1). We thus do not exclude any samples on this basis.

Degassing. Magmatic degassing can induce kinetic Tl isotope fractionation (Baker et al., 2009), theoretically producing residues with heavy $\mathrm{Tl}$ isotopic compositions and low $\mathrm{Tl}$ concentrations relative to incompatible refractory elements in contrast with condensates with isotopically light $\mathrm{Tl}$, though these have yet to be reliably identified in nature. Various ratios have been employed to assess sample degassing, including $\mathrm{Th} / \mathrm{Tl}$ (Nielsen et al., 2007), Pb/Tl (Rehkämper and Nielsen, 2004; Baker et al., 2009), Cs/Tl (Prytulak et al., 2013) and Ce/Tl (Nielsen et al., 2017a). The use of such ratios is challenging: Nielsen et al. (2017a) note that in arc settings, high $\mathrm{Ce} / \mathrm{Tl}$ ratios potentially indicative of kinetic processes are still lower than the average value for the upper mantle. In the current dataset, there is no co-variation indicative of degassing between $\varepsilon^{205} \mathrm{Tl}$ and relevant trace element concentrations or ratios for samples from individual volcanoes (not shown). This lack of chemical evidence is coupled with a lack of textural evidence for significant degassing, in that samples are thought to have been emplaced during effusive eruptions and show no significant vesicularity. Therefore, no data are rejected on this basis.

Post-depositional effects. In submarine lavas, both contamination (increasing the $\mathrm{Tl}$ contents of the rocks) and alteration (decreasing the $\mathrm{Tl}$ contents, via weathering) potentially cause resolvable differences in $\varepsilon^{205} \mathrm{Tl}$. As little as $1 \mu \mathrm{g}$ of FeMn oxyhydroxide coating per gram of sample can cause an analytically resolvable shift to heavier isotope signatures, while submarine alteration may efficiently strip $\mathrm{Tl}$ (at high temperatures) or add isotopically light $\mathrm{Tl}$ (at low temperatures) (Nielsen et al., 2006a). Samples exhibiting very low Tl concentration and $\varepsilon^{205} \mathrm{Tl}$ therefore require scrutiny for other evidence of alteration, whereas samples with very high $\mathrm{Tl}$ concentration and extreme $\varepsilon^{205} \mathrm{Tl}$ require scrutiny for contamination. A good example of the effects of alteration on $\mathrm{Tl}$ concentrations and isotopic compositions is provided by the study of Bluzstajn et al. (2018) on St. Helena lavas. In this case, a sample (SH-75) was excluded due to its high Tl concentration (339 ng/g) combined with an isotopic composition of $\varepsilon^{205} \mathrm{Tl}=-4.06$ and visual evidence of alteration. The 
authors consider surficial contamination by secondary clay minerals to be the most likely explanation for these features.

All OIB lavas analysed in this study were collected subaerially, although ambiguous records mean that it is unclear if the oldest Rurutu lavas were erupted in a subaerial or submarine environment (Chauvel et al., 1997). One Rurutu lava (RRT-037) shows the highest $\varepsilon^{205} \mathrm{Tl}$ value $(6.6 \pm 0.52 \mathrm{sd})$ reported for oceanic basalts thus far, warranting further assessment. However, rather than relying solely on chemical variation to identify such effects, five samples with $\varepsilon^{205} \mathrm{Tl}$ signatures significantly different from the mantle value were leached and reanalysed alongside USGS reference material BCR-2. The residues from the cold $\mathrm{HCl}$ leach retained $1 \%$ to $50 \%$ of the original $\mathrm{Tl}$, resulting in 0.05 to $1.9 \mathrm{ng} / \mathrm{g}$ total $\mathrm{Tl}$ available for analysis ( $6 \mathrm{ng} / \mathrm{g}$ for BCR-2), thus resulting in larger analytical errors for $\varepsilon^{205} \mathrm{Tl}$ (typically about $\pm 1 \varepsilon$ ). Notably, there is no systematic offset in $\varepsilon^{205} \mathrm{Tl}$ for the leached relative to the unleached sample powders (Table 2). This provides strong evidence that the positive and negative $\varepsilon^{205} \mathrm{Tl}$ end-members in our dataset are not due to surficial contamination. Therefore, we do not exclude any samples on this basis.

Assessment of subaerial post-depositional alteration is more challenging. These processes may remove $\mathrm{Tl}$ from the sample without significant $\mathrm{Tl}$ isotope fractionation. While large fractionations do arise in lowtemperature environments, strong mineralogical control is exerted by secondary sulphides in low-T hydrothermally altered oceanic crust (Coggon et al., 2014) and by birnessite in FeMn sediments (Peacock and Moon, 2012; Nielsen et al., 2013). Suspended riverine particulate matter, created through weathering, exhibits $\varepsilon^{205} \mathrm{Tl}$ very similar to that of loess, with the oxyhydroxide fraction generally containing only minor $\mathrm{Tl}$ that is not isotopically distinct (Nielsen et al., 2005). However, loss on ignition (LOI) is a traditional qualitative indicator of such alteration. All 48 analysed samples have LOI $<4 \%$, and 41 have LOI $<2 \%$. The seven samples with LOI $>2 \%$ were described as showing no identifiable petrological evidence of alteration (see Table 1 and references therein). Therefore, no data are excluded on this basis.

\section{Discussion}

We combine our new dataset with published studies to explore $\mathrm{Tl}$ behaviour at constructive plate margins and in intraplate settings. We first revisit the relative compatibility of $\mathrm{Tl}$ during mantle melting, then present models of $\mathrm{Tl}$ behaviour during MORB and OIB melting. Finally, we examine $\mathrm{Tl}$ isotope systematics 
alongside $\mathrm{Sr}-\mathrm{Nd}-\mathrm{Pb}$ radiogenic isotopic compositions in the global OIB dataset to explore implications for cycling of Tl through the solid Earth.

\subsection{Tl elemental systematics}

Thallium is highly incompatible during magmatic processes. Absolute Tl concentrations in OIB are thus principally determined by the extent of partial melting and fractional crystallisation. To compare the geochemistry of samples representing different degrees of melting, normalised incompatible element diagrams and ratios of trace elements with similar chemical partitioning are often employed. Quantitative assessment of how similarly two elements partition is theoretically straightforward: in a log-log plot of element concentrations, pairs of elements that partition identically produce a linear trend with a slope of unity (e.g. Sims and DePaolo, 1997). Such assessments are improved by taking into account the uncertainties in concentration for both elements (e.g. by using York regressions: York et al., 2004; Reed, 2010). In reality, however, analytical and statistical errors potentially obscure small deviations from linearity, especially between highly incompatible elements. It is therefore important to keep in mind that such relationships are at best indicative of relative compatibility contrasts. For MORB data, Nielsen et al. (2014) calculated that La, $\mathrm{Ce}$, and $\mathrm{Pb}$ had partitioning most similar to $\mathrm{Tl}$, with $\log [\mathrm{Tl}]-\log [\mathrm{Ce}]$ yielding a slope of $0.999 \pm 0.034$ (2sd, $n=594)$. Results for the expanded dataset incorporating Yang et al. (2018) are very similar (Table 3).

OIB clearly derive from heterogeneous sources. As such there is no expectation that log-log plots would provide anything other than a very approximate indication of relative partitioning. Indeed, even for samples from a single location there is a marked lack of coherence in log-log diagrams of $\mathrm{Tl}$ versus any trace element (not shown). Of all analysed elements, the closest approach to a slope of unity with $\log [\mathrm{Tl}]$ is achieved for $\log [\mathrm{Rb}]$, as found by Dupuy et al. (1973) for acidic volcanic rocks (Table 3). However, the uncertainty is so high that this is not a robust result. While lower uncertainties are achieved for $\log [\mathrm{Ce}]$ and $\log [\mathrm{La}]$, the slope does not approximate unity. Attempting to identify elements with similar bulk partition coefficients to $\mathrm{Tl}$ during OIB generation via log-log plots is therefore problematic.

Normalised incompatible element diagrams. Thallium has been placed both between La and Ce, for lowpressure fractionation of MORB (Jenner, 2017), and between Cs and Rb (Prytulak et al., 2017, following Dupuy et al., 1973). Given the ambiguity regarding placement and the lack of compelling indications from 
$\log -\log$ plots, we consider both compatibility orderings for the presentation of OIB data. Incompatible elements normalised to PM abundances are shown in Figure 2 (with normalisation to DM shown in Fig. S2). Notable is the marked negative $\mathrm{Tl}$ anomaly compared to other large-ion lithophile elements (47 of 48 samples) and REE (all samples). The La-Tl-Ce ordering produces visually similar $\mathrm{Tl}$ depletions to elements that are fluid-mobile during subduction processing, particularly $\mathrm{Pb}$. The co-variation is less striking for the $\mathrm{Cs}-\mathrm{Tl}-\mathrm{Rb}$ ordering, which might reflect the larger uncertainties of $\mathrm{Cs}$ abundances and/or the inferred greater similarity in fluid-mobile behaviour. Interestingly, the magnitude of the negative $\mathrm{Tl}$ anomaly co-varies with absolute $\mathrm{Tl}$ abundance, regardless of ordering (Fig. S3). Such co-variation would be anticipated if the ambient mantle contains negligible $\mathrm{Tl}$, such that increasing $\mathrm{Tl}$ abundances from exotic source(s) correlate directly with less negative $\mathrm{Tl}$ anomalies. In this scenario, the normalising PM (and DM) Tl concentration would be overestimated.

'Invariant' trace element ratios. Ratios of trace elements with similar partitioning are commonly used to 'see through' the effects of magmatic evolution: where partitioning is identical, ratios should be identical in source and product. However, selecting a suitable ratio for $\mathrm{Tl}$ in $\mathrm{OIB}$ is challenging. The $\mathrm{Cs} / \mathrm{Tl}$ ratio has been used, as partitioning of these two elements and their fluid mobility was assumed to be similar (e.g., Nielsen et al., 2006a; Prytulak et al., 2013; 2017). However, Cs/Tl can be affected by both degassing and possible sequestration of $\mathrm{Tl}$ in accessory minerals during subduction (e.g., Prytulak et al., 2013) and although Cs concentration determinations are routinely performed during ICP-MS analyses they often have relatively large errors due to the low abundance of $\mathrm{Cs}$ in igneous systems. The Ce/Tl ratio has also been used to assess Tl systematics in igneous settings, and has the advantage of a limited range in MORB (e.g. Nielsen et al., 2014, 2017b). As Tl partitioning is likely different between MORB and OIB regimes, no single ratio will be invariant for both tectonic settings.

In the new OIB dataset, $\mathrm{Ce} / \mathrm{Tl}$ varies over an order of magnitude at a similar degree of magmatic differentiation. While absolute $\mathrm{Tl}$ concentrations in OIB vary with $\mathrm{MgO}$ content, taken as a measure of the extent of differentiation, $\mathrm{Ce} / \mathrm{Tl}$ ratios do not (Fig. 3). Therefore, the range of Ce/Tl in OIB likely arises from some combination of source heterogeneity and melting processes. For example, Shu et al. (2019) observed a wide range of $\mathrm{Ce} / \mathrm{Tl}$ in subducted eclogites, which are geochemically similar to altered subducted oceanic crust that is thought to be a common component in OIB sources. Some authors have noted generally higher 
$\mathrm{Ce} / \mathrm{Tl}$ ratios in OIB compared to MORB (Nielsen et al., 2014; Blusztajn et al., 2018). When examining all available data, a clear tectonic distinction between MORB, arc and OIB lavas is apparent (Fig. 4): (1) arc lavas generally exhibit the lowest $\mathrm{Ce} / \mathrm{Tl}$ and highest $\mathrm{Tl}$ concentrations, alongside the most scattered distribution, even when filtered to exclude non-basaltic samples; (2) MORB Ce/Tl clusters around 1140, as previously discussed in Nielsen et al. (2014), and (3) global OIB form a remarkably coherent array that is clearly distinct from MORB, with overlap between the different mantle components defined by radiogenic isotopes. Similar patterns are observed for ratios of $\mathrm{Tl}$ with $\mathrm{Rb}, \mathrm{Cs}, \mathrm{La}$ and $\mathrm{Pb}$, though with these latter ratios the different tectonic settings are less clearly distinguished (Fig. S4), motivating the further focus on Ce/Tl systematics.

\subsection{Modelling Tl variations in MORB and OIB}

The systematic variation of $\mathrm{Tl}$ versus $\mathrm{Ce} / \mathrm{Tl}$ in global MORB and OIB can be explored with simple melting and mixing models (Fig. 5, 6). Fractional, non-modal melting models help explore the contrasting Ce/Tl patterns of MORB and OIB, though simplifying assumptions must be made for several parameters (Tables 46). Nielsen et al. (2014) identified constraints for the majority of these parameters for MORB generation, and modelled production of the "near-uniform" $\mathrm{Ce} / \mathrm{Tl}$ ratio for MORB through variation of S concentrations and associated $\mathrm{D}^{\mathrm{Tl}}$ sulf/sil values. However, subsequent findings warrant some re-evaluation of parameters.

While it is clear that $\mathrm{Tl}$ is hosted in sulphides to some extent, recent investigations into the partitioning of $\mathrm{Tl}$ indicates that it is less strongly chalcophile than previously assumed (e.g. Kiseeva and Wood, 2015; Wood and Kiseeva, 2015; Jenner, 2017; and see Appendix for detailed discussion). We therefore explored $\mathrm{D}^{\mathrm{Tl}}$ sulf/sil values between 1 and 25 and present results for $\mathrm{D}^{\mathrm{Tl}}{ }_{\text {sulf/sil }}=10$ (e.g. Kiseeva and Wood, 2013, 2015; see Appendix for detailed discussion). We also consider the effects of variation in $\mathrm{D}^{\mathrm{Ce}}{ }_{\text {cpx/melt }}$ between 0.01 and 0.8, which encompasses the wide range attributed to differences in mineral chemistry (Table 5; Appendix).

MORB. The MORB dataset in Figure 5 combines the studies of Jenner and O'Neill (2012), Nielsen et al. (2014) and Yang et al. (2018), excluding samples with $\mathrm{MgO}<6 \mathrm{wt} \%$, seamounts, back-arc basins and aseismic ridges. These studies yield a combined mean MORB Ce/Tl of $1220 \pm 570$ (2sd, n = 909).

Fractional melting models assuming a spinel lherzolite source with variations in $\mathrm{D}^{\mathrm{Ce}}{ }_{\text {cpx/melt }}$ and initial elemental concentration are shown in Figure 5, with the fractional melting model of Nielsen et al. (2014) 
reproduced in Figure 5a. We explore a range of $\mathrm{D}^{\mathrm{Ce}}{ }_{\mathrm{cpx} / \mathrm{melt}}$ in Figure 5b, reproducing not only the average $\mathrm{Ce} / \mathrm{Tl}$ value observed for MORB but also the sense of variation in the data. Compared to the model of Nielsen et al. (2014), the reduced compatibility of $\mathrm{Tl}$ in sulphides means that the model is less sensitive to the $\mathrm{S}$ concentration of the upper mantle. Considering only variations in the bulk partitioning of Ce, over $80 \%$ of MORB samples can be explained with a range of $\mathrm{D}^{\mathrm{Ce}}{ }_{\mathrm{cpx}}$ /melt up to $\sim 0.35$. Furthermore, about $50 \%$ of MORB samples are explained by $\mathrm{D}^{\mathrm{Ce}} \mathrm{cpx}_{\mathrm{melt}} \leq 0.2$, while fewer than $2 \%$ of MORB samples require $\mathrm{D}_{\mathrm{cpx} / \mathrm{melt}}^{\mathrm{Ce}}$ $\geq 0.8$.

We also present the effects of variation in initial $\mathrm{Tl}$ and Ce concentration on our melting model (Fig. 5c, 5d; Appendix), with $\mathrm{D}^{\mathrm{Ce}}{ }_{\mathrm{cpx} / \mathrm{melt}}=0.1$ (equivalent to bulk $\mathrm{D}^{\mathrm{Ce}}=0.015$, i.e. the average value for peridotite melting calculated by Stracke and Bourdon, 2009). Again, variation in either of these parameters can account for both the average $\mathrm{Ce} / \mathrm{Tl}$ ratio in MORB and the sense of the observed variation.

The models thus highlight two main points.

1. As previously noted, $\mathrm{MORB} \mathrm{Ce} / \mathrm{Tl}$ exhibits some variation with $\mathrm{Tl}$ concentration that exceeds measurement uncertainties (Nielsen et al., 2014). We suggest that Ce/Tl variations in MORB can be explained through a combination of melting effects, a range of $\mathrm{D}^{\mathrm{Ce}}{ }_{\mathrm{cpx} / \mathrm{melt}}$ associated with variations in the mineral composition of clinopyroxene, and variations in source concentrations of $\mathrm{Tl}$ and $\mathrm{Ce}$. Notably, this model does not require that bulk partition coefficients for Ce and Tl be approximately equal, and is nonetheless able to satisfy the constraint that a log-log concentration plot should exhibit a slope close to unity given the observed maximum concentration of $\mathrm{Tl}$ in MORB.

2. Regardless of the chosen value of $\mathrm{D}^{\mathrm{Ce}}{ }_{\mathrm{cp} / \mathrm{melt}}$, a model incorporating lower compatibility of $\mathrm{Tl}$ in sulphides than previously assumed yields a best fit for a $\mathrm{Tl}_{\mathrm{DM}}$ abundance of $0.27 \mathrm{ng} / \mathrm{g}$. This value is calculated assuming that (i) samples with the lowest $\mathrm{Tl}$ concentrations on average represent the highest degree of melting, i.e. the closest approach to the $\mathrm{DM} \mathrm{Ce} / \mathrm{Tl}$ ratio, and (ii) an average $\mathrm{Ce}_{\mathrm{DM}}$ of $0.55 \mu \mathrm{g} / \mathrm{g}$ (Workman and Hart, 2005). Our proposed $\mathrm{Tl}_{\mathrm{DM}}$ is considerably lower than the estimate of Salters and Stracke (2004) of $0.38 \mathrm{ng} / \mathrm{g}$, and much lower than that of Nielsen et al. (2014) of 0.48 $\mathrm{ng} / \mathrm{g}$. 
OIB. Fractional melting models assuming either a PM or a DM source (Table 4) with up to $15 \%$ melting are shown in Fig. 6a. It is immediately apparent that partial melting alone cannot produce the observed OIB

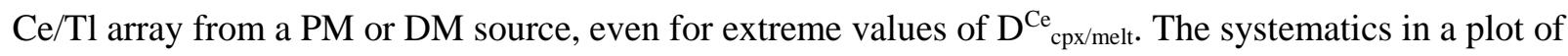
Tl/Ce versus Tl (Minster and Allègre, 1978; Fig. S5) emphasise that the observed range exceeds that which can be explained by partial melting and fractional crystallisation alone, consistent with longstanding radiogenic isotopic evidence for the heterogeneous and mixed nature of OIB sources. Notably, variations in $\mathrm{S}$ concentration or $\mathrm{D}^{\mathrm{Tl}}$ sulf/sil have no significant effect on model fit, but do affect the required degree of partial melting.

To explain the variation in the OIB array we first establish constraints on the mixed source compositions. In this context, solid state mixing is assumed, rather than mixing of partial melts of distinct components. Parameters including partition coefficients and initial elemental concentrations were varied until approximate matches between model output and the observed data array for up to 15\% melting were achieved (Fig. 6b). We then incorporate the assumption that OIB lavas are typically the product of $\sim 3-5 \%$ melting. In this scenario, the required source materials vary over an order of magnitude in terms of $\mathrm{Tl}$ concentration even within a single island (Fig. 6c, 6d). A striking feature of the model is that the majority of the array requires a source that is significantly more enriched in Ce than PM estimates, without similar enrichment in Tl. Indeed, most lavas require $\mathrm{Tl}$ source concentrations lower than PM estimates, and in some instances more depleted than DM. Of all the OIB samples analysed to date $(\mathrm{n}=93)$ only $10(\sim 11 \%)$ require a source $\mathrm{Tl}$ concentration $>3.5 \mathrm{ng} / \mathrm{g}$, i.e. more enriched in Tl than PM. Notably, although lavas from individual islands require source heterogeneity in terms of $\mathrm{Tl}$ concentration, lavas representing distinct radiogenic isotopic compositions have overlapping $\mathrm{Ce} / \mathrm{Tl}$ ranges.

The mixed source concentrations required by the OIB Ce/Tl array can be interpreted as a mantle 'background' that is extremely depleted in Tl, with addition of a material characterised by high Ce and heterogeneous $\mathrm{Tl}$ concentrations, broadly consistent with models of widespread addition of subducted materials to the mixed OIB source. However, prior to subduction surface materials with high Ce concentrations (e.g. FeMn sediments) also exhibit elevated $\mathrm{Tl}$ concentrations that greatly exceed values that can be accommodated by the mixing-melting model. If subducted materials are the exotic addition controlling $\mathrm{Ce} / \mathrm{Tl}$ systematics in $\mathrm{OIB}$, it is necessary that the majority of $\mathrm{Tl}$ must be removed or otherwise 
lost during subduction processing, rather than being recycled into the deep mantle. A $20 \%$ addition of such 'subduction-processed oceanic crust' (Table 6) to mantle strongly depleted in $\mathrm{Tl}$ would produce an appropriate mixed OIB source.

Recently, Shu et al. (2019) analysed the trace element and Tl isotopic composition of a number of eclogites subducted to a maximum depth of $\sim 90 \mathrm{~km}$ before being exhumed, which might represent such 'subductionprocessed' oceanic crust. This sample suite has an average Ce concentration of $20 \mu \mathrm{g} / \mathrm{g}$ with an average $\mathrm{Tl}$ concentration of $55 \mathrm{ng} / \mathrm{g}$ (Table 6). While the Ce concentration is consistent with the requirements for our proposed subduction-processed oceanic crust, the Tl concentration is an order of magnitude more than the maximum we invoke to satisfy our constraints on OIB source concentrations. However, as the eclogite samples remained within the stability field of Tl-rich phengite, it is likely that further Tl loss would occur during deeper subduction beyond the phengite stability field.

We agree with the findings of Shu et al. (2019) that OIB Ce/Tl systematics indicate widespread incorporation of subduction-processed oceanic crust into the OIB source, which may consist of (ancient, relatively enriched) oceanic crust with variable addition of a continental crust component. The Ce/Tl systematics of OIB thus highlight similarities, not differences, between mantle components distinguished by their radiogenic isotopic compositions. The complete overlap between different lavas representing distinct (enriched) mantle end-members strongly implies that a high-Ce, low-Tl material such as subductionprocessed oceanic crust is common to OIB sources, and that $\mathrm{Tl}$ is near quantitatively removed during subduction.

\subsection{Thallium isotopic composition of OIB}

The $\mathrm{Tl}$ isotopic composition of the mantle is strikingly homogeneous, and no resolvable $\mathrm{Tl}$ isotopic fractionation is observed during partial melting or fractional crystallisation. Therefore, the significant $\mathrm{Tl}$ isotopic variability observed in global OIB $\left(\varepsilon^{205} \mathrm{Tl}-10.0\right.$ to +6.6$)$ requires the addition of isotopically distinct material to the lavas. The addition of such material can happen in the source, en route to the surface, and/or via subaerial/submarine alteration. We have already argued that alteration does not play a significant role in the new data, and previous work has similarly screened and discounted altered samples. 
Thallium isotopic compositions were predicted to covary with the $\mathrm{Sr}-\mathrm{Nd}-\mathrm{Pb}$ radiogenic isotopes used to classify mantle components, depending on whether AOC or recycled sediments were the primary contributor of exotic material. However, the elemental systematics of Tl in OIB appear to require highly efficient removal of Tl during subduction, which potentially weakens the link between deep mantle recycling and OIB sources in terms of $\mathrm{Tl}$ isotopes. Indeed, the first order observation for our global dataset is that primary $\mathrm{Tl}$ isotopic compositions do not co-vary with radiogenic $\mathrm{Pb}, \mathrm{Sr}$, $\mathrm{Nd}$, or $\mathrm{Hf}$ isotopes (Fig. 7), even within the chemically diverse Marquesas island group. Although the range is large, the average $\varepsilon^{205} \mathrm{Tl}$ for HIMU and EM-type lavas overlap within error. For HIMU $\varepsilon^{205} \mathrm{Tl}=-2.6 \pm 6.6(2 \mathrm{~s}, \mathrm{n}=37)$, and for $\mathrm{EM} \varepsilon^{205} \mathrm{Tl}=-1.3 \pm 4.4$ $(2 \mathrm{~s}, \mathrm{n}=32)$. The overlap remains even if the comparison is restricted to main-phase St Helena lavas and EMI-type lavas, for which $\varepsilon^{205} \mathrm{Tl}=-3.2 \pm 3.1(2 \mathrm{~s}, \mathrm{n}=10)$ and $\varepsilon^{205} \mathrm{Tl}=-1.1 \pm 4.0(2 \mathrm{~s}, \mathrm{n}=13)$, respectively. The absence of correlation between $\mathrm{Tl}$ isotopic compositions and $\mathrm{Sr}-\mathrm{Nd}-\mathrm{Pb}-\mathrm{Hf}$ radiogenic isotope systems is consistent with trace element modelling that requires the mantle sources to be ubiquitously depleted in $\mathrm{Tl}$, likely due to near-quantitative removal of $\mathrm{Tl}$ during the subduction process. Elemental parent-daughter pairs for radiogenic isotopes do not show this same level of depletion in OIB sources, and thus $\mathrm{Tl}$ and radiogenic $\mathrm{Sr}-\mathrm{Nd}-\mathrm{Pb}-\mathrm{Hf}$ isotopic compositions can be easily decoupled, as noted by the first study of $\mathrm{Tl}$ isotopic composition in OIB (Nielsen et al. 2006a).

However, our finding that $\mathrm{Tl}$ isotope systematics may not be a straightforward "fingerprint" of recycled AOC or FeMn sediment to OIB source regions is at odds with previous work. While no variation in $\mathrm{Tl}$ isotopic composition was found in lavas from the Azores or Iceland (Nielsen et al., 2007), incorporation of deeply subducted FeMn sediment was invoked to explain variations observed in Hawai'ian picrites (Nielsen et al., 2006a), and HIMU-type St Helena basalts have been argued to show evidence for incorporation of subducted AOC (Blusztajn et al., 2018). In the case of Hawai'i, the absence of correlation between Tl stable and Os radiogenic isotopes was noted, despite the potential for FeMn sediment contributions to control both systems, and ascribed to the very high Tl/Os ratio such sediments exhibit.

Our new data provide a basis for re-evaluating the systematics of $\mathrm{Tl}$ isotopes in the HIMU mantle endmember. The isotopic criterion most commonly used to distinguish HIMU lavas is their radiogenic $\mathrm{Pb}$ isotopic compositions (i.e. ${ }^{206} \mathrm{~Pb} /{ }^{204} \mathrm{~Pb}>19.5$ ), which is commonly interpreted to arise from the subduction of AOC with high ${ }^{238} \mathrm{U} /{ }^{204} \mathrm{~Pb}$ ratios ('high $\mu$ '), that was isolated in the mantle for $1-2 \mathrm{Ga}$ (e.g. Hofmann and 
White, 1982; Zindler and Hart, 1986; Chauvel et al., 1992; Stracke et al., 2005). While acknowledging decoupling of $\mathrm{Tl}$ and $\mathrm{Sr}-\mathrm{Nd}-\mathrm{Hf}-\mathrm{Pb}$ isotopes, Blusztajn et al. (2018) argue that $\mathrm{Tl}$ isotopic compositions that are generally lighter than those found for MORB combined with $\mathrm{Ce} / \mathrm{Tl}$ variations provide evidence for the presence of a recycled upper AOC component in the St Helena source, from which up to $90 \%$ of $\mathrm{Tl}$ (relative to Ce) was stripped during subduction processing. Subsequent work investigated eclogites from Cabe Ortegal and the Raspas Complex, thought to represent the metamorphic equivalents of altered oceanic crust (Shu et al., 2019). The eclogites have a similar range in Tl isotopic compositions as the main phase St. Helena lavas $\left(\varepsilon^{205} \mathrm{Tl} \approx-5.5\right.$ to -1.0$)$, and thus Shu et al. (2019) proposed a genetic link between the two. This interpretation is complicated by the observation that, for the full OIB dataset (Fig. 8), the majority of HIMU samples have $\varepsilon^{205} \mathrm{Tl}$ values that overlap with the range of results obtained for EM-type samples $\left(\varepsilon^{205} \mathrm{Tl}\right.$ $\geqslant-6.5$; Fig. $8 \mathrm{~b}, 8 \mathrm{~d})$. In addition, there is no convincing co-variation of $\varepsilon^{205} \mathrm{Tl}$ with $\mathrm{Ce} / \mathrm{Tl}$ and $\mathrm{Ce} / \mathrm{Pb}$ for either St Helena lavas (Fig. 8a, 8c) or the complete OIB dataset, with EM-type samples again overlapping the whole range of HIMU-type lavas. While one HIMU-type lava does exhibit the lightest reported $\mathrm{Tl}$ isotopic composition of any OIB sampled to date $\left(\varepsilon^{205} \mathrm{Tl} \approx-10\right)$, the broad overlap in $\varepsilon^{205} \mathrm{Tl}$ for HIMU- and EM-type OIB does not provide a clear distinction between different mantle end-members based on $\mathrm{Tl}$ isotopic compositions alone. It therefore appears that $\mathrm{Tl}$ isotopic compositions are decoupled not just from radiogenic isotopes and Tl concentrations, as suggested by Shu et al. (2019), but also - at least on a global scale - from incompatible trace element ratios held to be indicative of AOC contributions.

We concur with the conclusion of Blusztajn et al. (2018) that the Ce/Tl ratios of OIB appear to be broadly complementary to those found in island arc lavas. It is therefore necessary to explain how $\mathrm{Tl}$ isotopic systematics become (apparently) decoupled from $\mathrm{Tl}$ elemental systematics. Fitting our model to elemental systematics data requires highly efficient ( $99 \%$, relative to $\mathrm{Ce}$ ) removal of $\mathrm{Tl}$ from heterogeneous subducting materials, with only a small proportion of subducted Tl returned to OIB source regions in the deep mantle. Therefore, the low $\mathrm{Tl}$ concentrations of the OIB sources produce magmas with $\mathrm{Tl}$ signatures that can be readily overprinted by addition of isotopically distinct material.

The notion that $\mathrm{Tl}$ isotopic compositions distinct from mantle values are due to the input of $\mathrm{Tl}$-rich, isotopically distinct materials can be further examined via the magnitude of the negative $\mathrm{Tl}$ concentration anomaly observed for OIB relative to geochemically similar elements. When the magnitude of the $\mathrm{Tl}$ 
anomaly $\mathrm{Tl} / \mathrm{Tl}^{*}$ (see caption to Figure 9 ) is plotted against $\mathrm{Tl}$ isotopic composition, samples with $\mathrm{Tl} / \mathrm{Tl} 1^{*}>$ $\sim 0.5$ (calculated relative to $\mathrm{Cs}$ and $\mathrm{Rb}$ ) generally have $\mathrm{Tl}$ isotopic compositions that differ from the mantle (Fig. 9a, 9b). As would be expected given the decoupling of $\mathrm{Tl}$ and radiogenic isotopic compositions, this pattern is not restricted to or consistent within any one radiogenic isotope end-member, and some samples with $\mathrm{Tl} / \mathrm{Tl}^{*}<\sim 0.5$ also display non-mantle values. Ruling out post-depositional isotopic effects, the question that arises is where does the addition of material with non-mantle $\mathrm{Tl}$ isotopic compositions take place? The mantle source or en route to eruption?

Addition of isotopically distinct $\mathrm{Tl}$ to the OIB source via residual $\mathrm{Tl}$ from a subduction-processed slab and/or addition during ascent through the crust via assimilation of country rock, including sediments and previously-erupted and subsequently altered lavas are both reasonable processes. For example, variation in the extent and type of material assimilated during different stages of magmatism might account for the distinct average Tl isotopic compositions observed by Blusztajn et al. (2018) for St Helena early-, main-, and late-stage lavas. Given the $\mathrm{Tl}$ concentration contrast between magma and potential inputs, neither origin for $\mathrm{Tl}$ isotope variations - source heterogeneity or assimilation - would necessarily cause resolvable changes to other geochemical markers (e.g. model of Nielsen et al., 2006a; Fig. S6). Caution is therefore advisable when interpreting $\mathrm{Tl}$ isotopic compositions of OIB as a direct reflection of the mantle source. However, there is the potential that variable crustal assimilation of isotopically distinct $\mathrm{Tl}$ might be identifiable in high resolution studies of lavas from individual volcanic edifices, yielding insight into their magmatic plumbing architecture.

\section{Conclusions}

Fresh lavas from divergent, convergent and intraplate settings can be distinguished by their distinct systematics in plots of $\mathrm{Ce} / \mathrm{Tl}$ versus $\mathrm{Tl}$ concentrations. The observed patterns can be reproduced by models of fractional, non-modal melting, providing insights into the cycling of $\mathrm{Tl}$ through the mantle. The Ce/Tl systematics of MORB can be reproduced by the combined effects of different extents of partial melting and variations in $\mathrm{D}^{\mathrm{Ce}}{ }_{\text {cpx/melt }}$ and initial $\mathrm{Tl}$ and Ce concentrations, without a significant role for sulfides. In contrast, the $\mathrm{Ce} / \mathrm{Tl}$ systematics of OIB cannot be generated from a primitive mantle source, but instead require a source that is markedly depleted in $\mathrm{Tl}(<1 \mathrm{ng} / \mathrm{g})$ prior to addition of exotic thallium. The requirement for $\mathrm{Tl}-$ depleted OIB source regions is consistent with mounting evidence that the extent of present day mantle depletion may be underestimated (e.g. Stracke, 2012; Stracke et al., 2011, 2019; Salters et al., 2011; Salters 
and Dick, 2002; Cipriani et al., 2004; Sanfillippo et al., 2019). The OIB array can be generated from a depleted mantle source with addition of up to $20 \%$ subducted material from which $>99 \%$ of $\mathrm{Tl}$ has been stripped during subduction processing. This suggests that $\mathrm{Tl}$ constitutes an extreme example of the behaviour of fluid-mobile elements in subduction zone settings, such that co-variations of $\mathrm{Tl}$ with other elements may further constrain elemental subduction zone cycling.

Thallium and radiogenic isotopic compositions are decoupled, and $\mathrm{Tl}$ isotopic compositions cannot be used in isolation to distinguish between continental and oceanic crust contribution to OIB source regions. The observed decoupling of $\mathrm{Tl}$ and radiogenic isotopic compositions most likely reflects (1) the sensitivity of $\mathrm{Tl}$ to small variations in the isotopic composition of residual $\mathrm{Tl}$, and/or (2) the extreme $\mathrm{Tl}$ concentration contrast between mantle and surface materials. Despite the lack of co-variation with radiogenic isotopes, global OIB display a significant range in primary $\mathrm{Tl}$ isotopic compositions which must reflect addition of isotopically distinct material. However, where this $\mathrm{Tl}$ addition takes places remains ambiguous. The potential incorporation of Tl-rich materials at crustal levels during magma ascent is a feasible alternative interpretation to the generation of $\mathrm{Tl}$ isotopic variability due to incorporation of residual slab-derived $\mathrm{Tl}$ at mantle depths following subduction processing.

\section{Acknowledgements}

$\mathrm{AB}$ was funded by an Imperial College London Earth Science and Engineering Janet Watson departmental PhD scholarship with all analytical costs covered by start-up funds to JP. We thank Barry Coles and Katharina Kreissig for keeping the MAGIC instruments and clean labs running smoothly. CC was supported in part by ERC project SHRED (project 833632), and this is contribution 4149 of the IPGP. We appreciate the comments of Folkmar Hauff, Kevin Konrad, four anonymous reviewers, and the editorial handling of James Day, all of which helped improve the manuscript.

\section{Appendix}

\section{Elemental concentrations}

MORB. For Ce concentration, we use the values of Workman and Hart (2005) for Depleted MORB Mantle (DMM), Enriched MORB Mantle (EMM), and the average MORB source. For Tl concentration, we consider previous DMM estimates along with values that provide the best fit for our model. 
OIB. We used the values of McDonough and Sun (1995) as our initial values for PM, then varied concentrations as required to fit our model to the data.

\section{Thallium partitioning}

Chalcophilia. Nielsen et al. (2014) based their values of $\mathrm{D}^{\mathrm{Tl}}$ sulf/sil during MORB melting (18-100) on data from Kiseeva and Wood (2013), who reported $\mathrm{D}^{\mathrm{Tl}}$ sulf/sil $=4-24$. However, a growing body of evidence supports the concept that "mixed affinity" behaviour is exhibited by Tl, i.e. elemental behaviour cannot be described as either predominantly chalcophile or predominantly lithophile.

Kiseeva and Wood (2015) report $\mathrm{D}^{\mathrm{Tl}}$ sulf/sil of 4-33, and note that "partitioning of most elements is a strong function of the oxygen (or FeO) content of the sulphide", which "increases linearly with the FeO content of the silicate melt and decreases with the Ni content of the sulphide." Wood and Kiseeva (2015) go on to state that $\mathrm{Tl}$ partitioning does not obey this simple model, nor one extended through consideration of additional parameters: "Despite simple and predictable partitioning behavior for many elements, several important elements $(\mathrm{Ni}, \mathrm{Cu}, \mathrm{Ag}, \mathrm{Mn}, \mathrm{Tl})$ show strongly non-linear dependences of $\log D_{\mathrm{i}}$ on $\log [\mathrm{FeO}]$ and we were unable to assign them to any one particular category in terms of affinity for sulfide."

Jenner (2017) calculated that for typical MORB melting $\mathrm{D}_{\text {sulf } / \mathrm{sil}}^{\mathrm{Tl}}=7$; Greaney et al. (2017) observe mixed affinity behaviour during magmatic differentiation at Kilauea Iki. Wang et al. (2018) suggested that a significant proportion of the $\mathrm{Tl}$ contents of peridotites are hosted in interstitial late-crystallising silicate phases, finding that sulphides typically contribute $<30 \%$ of the bulk rock $\mathrm{Tl}$ budget. These observations are consistent with poor correlation of $\mathrm{Tl}$ concentrations with chalcophile element concentrations in most igneous contexts (e.g. Prytulak et al., 2017).

Silicate minerals. Although $\mathrm{Tl}$ is known to be highly incompatible, partitioning of $\mathrm{Tl}$ between silicate minerals and melt remains poorly constrained. Nielsen et al. (2014) therefore assumed $\mathrm{D}^{\mathrm{Tl}}{ }_{\mathrm{min} / \mathrm{melt}}$ identical to $\mathrm{D}^{\mathrm{Rb}}{ }_{\text {min/melt }}$ due to the similarity in ionic charge and radius. $\mathrm{Tl}^{+}$is well-known to substitute for $\mathrm{K}^{+}$in silicate minerals (e.g. Shaw et al 1952), as documented by e.g. Rader et al. (2018), and we also assume similar partitioning behaviour of $\mathrm{Rb}$ and $\mathrm{Tl}$ in silicate contexts.

\section{Cerium partitioning}


Although variation in mineral-melt partitioning of Ce between clinopyroxene and basaltic melt (herein $\left.\mathrm{D}^{\mathrm{Ce}}{ }_{\text {cpx/melt }}\right)$ is not required to model the MORB Ce/Tl array, it is likely that such variation does exist and does contribute to the observed pattern. The GERM database (as of June 2020) documents a total range in $\mathrm{D}^{\mathrm{Ce}}{ }_{\text {cpx/melt }}$ from 0.017 (Frey, 1969) to 0.82 (Vannucci et al., 1998), excluding the values of Nagasawa (1973), which were determined on natural samples showing signs of significant alteration (Uchimizu, 1966). $\mathrm{D}^{\mathrm{Ce}} \mathrm{cpx/melt}_{\text {is }}$ is generally observed to increase with increasing Wollastonite and tetrahedrally-coordinated $\mathrm{Al}$ content of clinopyroxene. The data compilation of Sun and Liang (2012) features a range of $\mathrm{D}^{\mathrm{Ce}}{ }_{c p x / m e l t}$ from 0.019 (Salters and Longhi, 1999) to 0.27 (Gaetani and Grove, 1995), excluding the data of Wood and Trigila (2001) determined for highly potassic melts ( $\mathrm{D}^{\mathrm{Ce}}{ }_{\mathrm{cpx}}$ /melt from 0.48 to 1.31$)$. This information is presented graphically in Figure A1.

Johnston and Schwab (2004) additionally determined a $\mathrm{D}^{\mathrm{Ce}}{ }_{\text {ppx/melt }}$ value of 0.47 during experiments on the partial melting of peridotite (not shown). Further data for partitioning of REE in the presence of high-Ca clinopyroxenes was compiled by Bédard (2014), though the dataset for terrestrial basalts is limited.

While Sun and Liang (2012) provided recommended values for $\mathrm{D}_{\mathrm{cpx} / \mathrm{melt}}^{\mathrm{Ce}}$ during MORB melting, they note that these values are based on highly simplified thermodynamic models of clinopyroxene that may represent unrealistically restricted mineral composition ranges. We therefore explore a range of $\mathrm{D}^{\mathrm{Ce}}{ }_{\text {ppx/melt }}$ from 0.01 to 0.8 in our modelling. We do not consider 0.8 a value that is likely to be achieved in natural rocks, but it is informative as an end-member scenario.

\section{References}

Adam J. and Green T. (2006) Trace-element partitioning between mica- and amphibole-bearing garnet lherzolite and hydrous basanitic melt: 1 . Experimental results and the investigation of controls on partitioning behaviour. Contrib. Mineral. Petrol. 152, 1-17. doi:10.1007/s00410-006-0085-4

Bach W., Erzinger J., Alt J. C. and Teagle D. A. H. (1996) 4. Chemistry of the lower sheeted dike complex, Hole 504B (Leg 148): influence of magmatic differentiation and hydrothermal alteration. Proc. ODP Sci. Results 148, 39-55.

Baker M.B. and Stolper E.M. (1994) Determining the composition of high-pressure mantle melts using diamond aggregates. Geochim. Cosmochim. Acta 58, 2811-2827. doi:10.1016/0016-7037(94)90116-3

Baker R. G. A., Rehkämper M., Hinkley T. K., Nielsen S. G. and Toutain J. P. (2009) Investigation of thallium fluxes from subaerial volcanism-Implications for the present and past mass balance of thallium in the oceans. Geochim. Cosmochim. Acta 73, 6340-6359. doi:10.1016/j.gca.2009.07.014 
Bebout, G. E. (2007) Metamorphic chemical geodynamics of subduction zones. Earth Planet. Sci. Lett. 260, $373-393$. doi:10.1016/j.eps1.2007.05.050

Bédard J. H. (2013) Parameterizations of calcic clinopyroxene - melt trace element partition coefficients. Geochem. Geophys. Geosys. 15, 303-336. doi:10.1002/2013GC005112

Blundy J. D., Robinson J. A. C. and Wood B. J. (1998) Heavy REE are compatible in clinopyroxene on the spinel lherzolite solidus. Earth Planet. Sci. Lett. 160, 493-504. doi:10.1016/S0012-821X(98)00106-X

Blusztajn J., Nielsen S. G., Marschall H. R., Shu Y., Ostrander C. M. and Hanyu T. (2018) Thallium isotope systematics in volcanic rocks from St Helena - constraints on the origin of the HIMU reservoir. Chem. Geol. 476, 292-301. doi:10.1016/j.chemgeo.2017.11.025

Bo T., Katz R. F., Shorttle O. and Rudge, J. F. (2018) The melting column as a filter of mantle trace-element Heterogeneity. Geochem. Geophys. Geosyst. 19, 4694-4721. doi:10.1029/2018GC007880

Brett E. K. A., Prytulak J., Hammond S. J. and Rehkämper M. (2018). Thallium concentration and stable isotope compositions of sixteen international reference materials. Geostand. Geoanal. Res. 42, 339-360. doi:10.1111/ggr.12215

Chauvel C., Hofmann A. W. and Vidal P. (1992) HIMU-EM: The French Polynesian connection. Earth Planet. Sci. Lett. 110, 99-119. doi:10.1016/0012-821X(92)90042-T

Chauvel C., McDonough W., Guille G., Maury R. and Duncan R. (1997) Contrasting old and young volcanism in Rurutu Island, Austral chain. Chem. Geol. 139, 125-143. doi:10.1016/S0009-2541(97)00029-6

Chauvel C., Maury R. C., Blais S., Lewin E., Guillou H., Guille G., Rossi P. and Gutscher M. A. (2012) The size of plume heterogeneities constrained by Marquesas isotopic stripes. Geochem. Geophys. Geosyst. 13, Q07005. doi:10.1029/2012GC004123

Cipriani A., Brueckner H. K., Bonatti E. and Brunelli D. (2004) Oceanic crust generated by elusive parents: Sr and Nd isotopes in basalt-peridotite pairs from the Mid-Atlantic Ridge. Geology 32, 657-660. doi:10.1130/G20560.1

Coggon R. M., Rehkämper M., Atteck C., Teagle D. A. H., Alt J. C. and Cooper M. J. (2014) Controls on thallium uptake during hydrothermal alteration of the upper ocean crust. Geochim. Cosmochim. Acta 144, 25-42. doi:10.1016/j.gca.2014.09.001

Cox D., Watt S. F. L., Jenner F. E., Hastie A. R. and Hammond S. J. (2019) Chalcophile element processing beneath a continental arc stratovolcano. Earth Planet. Sci. Lett. 522, 1-11. doi:10.1016/j.eps1.2019.06.017

Ding S. and Dasgupta R. (2018) Sulfur inventory of Ocean Island Basalt source regions constrained by modeling the fate of sulfide during decompression melting of a heterogeneous mantle. J. Petrol. 59, 1281-1308. doi:10.1093/petrology/egy061

Donnelly K. E., Goldstein S. L., Langmuir C. H. and Spiegelman M. (2004) Origin of enriched ocean ridge basalts and implications for mantle dynamics. Earth Planet. Sci. Lett. 226, 347-366. doi:10.1016/j.eps1.2004.07.019

Dupuy C., Fratta M. and Shaw D. M. (1973) Partition coefficient of thallium compared with rubidium. Earth Planet. Sci. Lett. 19, 209-212. doi:10.1016/0012-821X(73)90116-7 
Eggins S. M., Woodhead J. D., Kinsley L. P. J., Mortimer G. E., Sylvester P., McCulloch M. T. Hergt J. M. and Handler M. R. (1997) A simple method for the precise determination of $\geq 40$ trace elements in geological samples by ICPMS using enriched isotope internal standardisation. Chem. Geol. 134, 311-326. doi:10.1016/S00092541(96)00100-3

Elliott T., Blichert-Toft J., Heumann A., Koetsier G. and Forjaz V. (2007) The origin of enriched mantle beneath São Miguel, Azores. Geochim. Cosmochim. Acta 71, 219-240. doi:10.1016/j.gca.2006.07.043

Fitzpayne A., Prytulak J., Giuliani A. and Hergt J. (2020) Thallium isotopic composition of phlogopite in kimberlitehosted MARID and PIC mantle xenoliths. Chem. Geol. 531, 119347. doi:10.1016/j.chemgeo.2019.119347

Frey F. A. (1969) Rare earth abundances in a high-temperature peridotite intrusion. Geochim. Cosmochim. Acta 33, 1429-1447. doi:10.1016/0016-7037(69)90183-5

Gaetani G. A. and Grove T. L. (1995) Partitioning of rare earth elements between clinopyroxene and silicate melt: crystal-chemical controls. Geochim. Cosmochim. Acta 59, 1951-1962. doi:10.1016/0016-7037(95)00119-0

Gaetani G. A., Kent A., Grove T. L., Hutchenson I. and Stolper E. M. (2003) Mineral/melt partitioning of trace elements during hydrous peridotite partial melting. Contrib. Mineral. Petrol. 145, 391-405. doi:10.1016/00167037(95)00119-0

Gale A., Dalton C. A., Langmuir C. H., Su Y., Schilling J. G. (2013) The mean composition of ocean ridge basalts. Geochem. Geophys. Geosyst. 14, 489-518. doi:10.1029/2012GC004334

Greaney A. T., Rudnick R. L., Helz R. T., Gaschnig R. M., Piccoli P. M. and Ash R. D. (2017) The behavior of chalcophile elements during magmatic differentiation as observed in Kilauea Iki lava lake, Hawaii. Geochim. Cosmochim. Acta 210, 71-96. doi:10.1016/j.gca.2017.04.033

Green T. H., Blundy J. D., Adam J. and Yaxley G. M. (2000) SIMS determination of trace element partition coefficients between garnet, clinopyroxene, and hydrous basaltic liquids at 2-7.5 GPa and 1080-1200 ${ }^{\circ}$. Lithos 53, $165-187$. doi:10.1016/S0024-4937(00)00023-2

Hauri E. H., Wagner T. P. and Grove T. L. (1994) Experimental and natural partitioning of Th-U-Pb and other trace elements between garnet, clinopyroxene and basaltic melts. Chem. Geol. 117, 149-166. doi:10.1016/00092541(94)90126-0

Heinrichs H., Schulz-Dobrick B. and Wedepohl K. H. (1980) Terrestrial geochemistry of Cd, Bi, Tl, Pb, Zn and Rb. Geochim. Cosmochim. Acta 44, 1519-1533. doi:10.1016/0016-7037(80)90116-7

Hill E., Wood B. J. and Blundy J. D. (2000) The effect of Ca-Tschermaks component on trace element partitioning between clinopyroxene and silicate melt. Lithos 53, 205-217. doi:10.1016/S0024-4937(00)00025-6

Hofmann A. W. (1997) Mantle geochemistry: the message from oceanic volcanism. Nature 385, $219-229$. doi: $10.1038 / 385219 \mathrm{a} 0$

Hofmann A. W. and White W. M. (1982) Mantle plumes from ancient oceanic crust. Earth Planet. Sci. Lett. 57, 421436. doi:10.1016/0012-821X(82)90161-3 
Irving A. J. and Frey F. A. (1984) Trace element abundances in megacrysts and their host basalts: constraints on partition coefficients and megacryst genesis. Geochim. Cosmochim. Acta 48, 1201-1221. doi:10.1016/00167037(84)90056-5

Jenner F. E. (2017) Cumulate causes for the low contents of sulfide-loving elements in the continental crust. Nat. Geosci. 10, 524-529. doi:10.1038/ngeo2965

Jenner F. and O'Neill H. St. C. (2012). Analysis of 60 elements in 616 ocean floor basaltic glasses. Geochem. Geophys. Geosyst. 13, Q02005. doi:10.1029/2011GC004009

Johnson K. T. M. (1998) Experimental determination of partition coefficients for rare earth and high-field-strength elements between clinopyroxene, garnet, and basaltic melt at high pressures. Contrib. Mineral. Petrol. 133, 60-68. doi: $10.1007 / \mathrm{s} 004100050437$

Johnston A. D. and Schwab B. E. (2004) Constraints on clinopyroxene/melt partitioning of REE, Rb, Sr, Ti, Cr, Zr, and $\mathrm{Nb}$ during mantle melting: first insights from direct peridotite melting experiments at 1.0 GPa. Geochim. Cosmochim. Acta 68, 4949-4962. doi:10.1016/j.gca.2004.06.009

Kiseeva E. S. and Wood B. J. (2013) A simple model for chalcophile element partitioning between sulphide and silicate liquids with geochemical applications. Earth Planet. Sci. Lett. 383, 68-81. doi:10.1016/j.epsl.2013.09.034

Kiseeva E. S. and Wood B. J. (2015) The effects of composition and temperature on chalcophile and lithophile element partitioning into magmatic sulphides. Earth Planet. Sci. Lett. 424, 280-294. doi:10.1016/j.epsl.2015.05.012

Klemme S., Blundy J. D. and Wood B. J. (2002) Experimental constraints on major and trace element partitioning during partial melting of eclogite. Geochim. Cosmochim. Acta 66, 3109-3123. doi:10.1016/S0016-7037(02)00859-1

Liu Y., Samaha N.-T. and Baker D. R. (2007) Sulfur concentration at sulfide saturation (SCSS) in magmatic silicate melts. Geochim. Cosmochim. Acta 71, 1783-1799. doi:10.1016/j.gca.2007.01.004

Liu B. and Liang Y. (2020) Importance of the size and distribution of chemical heterogeneities in the mantle source to the variations of isotope ratios and trace element abundances in mid-ocean ridge basalts. Geochim. Cosmochim. Acta 268, 383-404. doi:10.1016/j.gca.2019.10.013

Matsui Y., Onuma N., Nagasawa H., Higuchi H. and Banno S. (1977) Crystal structure control in trace element partitioning between crystal and magma. Tectonics 100, 315-324.

Mavrogenes J. A. and O’Neill H. St. C. (1999) The relative effects of pressure, temperature and oxygen fugacity on the solubility of sulfide in mafic magmas. Geochim. Cosmochim. Acta 63, 1173-1180. doi:10.1016/S00167037(98)00289-0

McDade P., Blundy J. D. and Wood B. J. (2003a) Trace element partitioning on the Tinaquillo Lherzolite solidus at 1.5 GPa. Phys. Earth Planet. Int. 139, 129-147. doi:10.1016/S0031-9201(03)00149-3

McDade P., Blundy J. D. and Wood B.J. (2003b) Trace element partitioning between mantle wedge peridotite and hydrous MgO-rich melt. Am Mineral. 88, 1825-1831. doi:10.2138/am-2003-11-1225

McDonough W. F. and Sun S.-s. (1995) The composition of the earth. Chem. Geol. 120, 223-253. doi:10.1016/00092541(94)00140-4 
Minster J. F. and Allègre C. J. (1978) Systematic use of trace elements in igneous processes. Contrib. Mineral. Petrol. 68, 37-52. doi:10.1007/BF00375445

Montelli R., Nolet G., Dahlen F. A. and Masters G. (2006) A catalogue of deep mantle plumes: New results from finitefrequency tomography. Geochem. Geophys. Geosyst. 7, Q11007. doi:10.1029/2006GC001248

Morgan W. J. (1971) Convection plumes in the lower mantle. Nature 230, 42-43. doi:10.1038/230042a0

Nagasawa H., Wakita H., Higuchi H. and Onuma N. (1969) Rare Earths in peridotite nodules: an explanation of the genetic relationship between basalt and peridotite nodules. Earth Planet. Sci. Lett. 5, 377-381. doi:10.1016/S0012$821 X(68) 80067-6$

Nagasawa H. (1973). Rare-Earth distribution in alkali rocks from Oki-Dogo Island, Japan. Contrib. Mineral. Petrol. 39, 301-308. doi:10.1007/BF00376470

Nielsen S. G., Rehkämper M., Baker J. and Halliday A. N. (2004) The precise and accurate determination of thallium isotope compositions and concentrations for water samples by MC-ICPMS. Chem. Geol. 204, 109-124. doi:10.1016/j.chemgeo.2003.11.006

Nielsen S. G., Rehkämper M., Porcelli D., Andersson P., Halliday A. N., Swarzenski P. W., Latkoczy C. and Günther D. (2005) Thallium isotope composition of the upper continental crust and rivers - an investigation of the continental sources of dissolved marine thallium. Geochim. Cosmochim. Acta 19, 2007-2019. doi:10.1016/j.gca.2004.10.025

Nielsen S. G., Rehkämper M., Norman M. D., Halliday A. N. and Harrison D. (2006a). Thallium isotopic evidence for ferromanganese sediments in the mantle source of Hawaiian basalts. Nature 439, 314-317. doi:10.1038/nature04450

Nielsen S. G., Rehkämper M., Teagle D. A. H., Butterfield D. A., Alt J. C. and Halliday A. N. (2006b) Hydrothermal fluid fluxes calculated from the isotopic mass balance of thallium in the ocean crust. Earth Planet. Sci. Lett. 251, 120-133. doi:10.1016/j.eps1.2006.09.002

Nielsen S. G., Rehkämper M., Brandon A. D., Norman M. D., Turner S. and O’Reilly S. Y. (2007) Thallium isotopes in Iceland and Azores lavas - implications for the role of altered crust and mantle geochemistry. Earth Planet. Sci. Lett. 264, 332-345. doi:10.1016/j.eps1.2007.10.008

Nielsen S.G., Wasylenki L. E., Rehkämper M., Peacock C. L., Xue Z. and Moon E. M. (2013) Towards an understanding of thallium isotope fractionation during adsorption to manganese oxides. Geochim. Cosmochim. Acta 117, 252-265. doi:10.1016/j.gca.2013.05.004

Nielsen S. G., Shimizu N., Lee C. T. A. and Behn M. D. (2014) Chalcophile behaviour of thallium during MORB melting and implications for the sulfur content of the mantle. Geochem. Geophys. Geosyst. 15, 4905-4919. doi:10.1002/2014GC005536

Nielsen S. G., Klein F., Kading T., Blusztajn J. and Wickham K. (2015). Thallium as a tracer of fluid-rock interaction in the shallow Mariana forearc. Earth Planet. Sci. Lett. 430, 416-426. doi:10.1016/j.eps1.2015.09.001 
Nielsen S. G., Yogodzinski G., Prytulak J., Plank T., Kay S. M., Kay R. W., Blusztajn J., Owens J. D., Auro M. and Kading T. (2016) Tracking along-arc sediment inputs to the Aleutian arc using thallium isotopes. Geochim. Cosmochim. Acta 181, 217-237. doi:10.1016/j.gca.2016.03.010

Nielsen S.G., Prytulak J., Blusztajn J., Shu Y., Auro M., Regelous M. and Walker J. (2017a) Thallium isotopes as tracers of recycled materials in subduction zones: review and new data for lavas from Tonga-Kermadec and Central America. J. Vol. Geotherm. Res. 339, 23-40. doi:10.1016/j.jvolgeores.2017.04.024

Nielsen S. G., Prytulak J. and Rehkämper M. (2017b) Investigation and application of thallium isotope fractionation. Rev. Mineral. Geochem. 82, 799-850. doi:10.2138/rmg.2017.82.18

O’Neill H. St. C. and Mavrogenes J. A. (2002) The sulfide capacity and the sulfur content at sulfide saturation of silicate melts at $1400^{\circ} \mathrm{C}$ and 1 bar. J. Petrol. 43, 1049-1087. doi:10.1093/petrology/43.6.1049

Palme H. and O’Neill H. St. C. (2014) Cosmochemical Estimates of Mantle Composition. In The Mantle and Core 2 (eds. D. H. Heinrich and K. T. Karl). Elsevier, Amsterdam. pp. 1-38.

Peacock C. L. and Moon E. M. (2012) Oxidative scavenging of thallium by birnessite: explanation for thallium enrichment and stable isotope fractionation in marine ferromanganese precipitates. Geochim. Cosmochim. Acta 84, 297-313. doi:10.1016/j.gca.2012.01.036

Piper D. Z. (1974) Rare earth elements in ferromanganese nodules and other marine phases. Geochim. Cosmochim. Acta 38, 1007-1022. doi:10.1016/0016-7037(74)90002-7

Prytulak J., Nielsen S. G., Plank T., Barker M. and Elliott T. (2013). Assessing the utility of thallium and thallium isotopes for tracing subduction zone inputs to the Mariana arc. Chem. Geol. 345, 129-149. doi:10.1016/j.chemgeo.2013.03.003

Prytulak J., Brett E. K. A., Webb M., Rehkämper M., Plank T., Savage P.S. and Woodhead J. (2017) Thallium elemental behavior and stable isotope fractionation during magmatic processes. Chem. Geol. 448, 71-83. doi:10.1016/j.chemgeo.2016.11.007

Rader S. T., Mazdab F. K. and Barton M. D. (2018) Mineralogical thallium geochemistry and isotope variations from igneous, metamorphic, and metasomatic systems. Geochim. Cosmochim. Acta 243, 42-65. doi:10.1016/j.gca.2018.09.019

Reed, B.C. (2010) A spreadsheet for linear least-squares fitting with errors in both coordinates. Phys. Ed. 45, 93-96. doi:10.1088/0031-9120/45/1/011

Rehkämper M. and Halliday A. N. (1999) The precise measurement of Tl isotopic compositions by MC-ICPMS: application to the analysis of geological materials and meteorites. Geochim. Cosmochim. Acta 63, 935-944. doi:10.1016/S0016-7037(98)00312-3

Rehkämper M., Frank M., Hein J. R., Porcelli D., Halliday A., Ingri J. and Liebetrau V. (2002) Thallium isotope variations in seawater and hydrogenetic, diagenetic, and hydrothermal ferromanganese deposits. Earth Planet. Sci. Lett. 197, 65-81. doi:10.1016/S0012-821X(02)00462-4

Rehkämper M. and Nielsen S. G. (2004) The mass balance of dissolved thallium in the oceans. Mar. Chem. 85, 125139. doi:10.1016/j.marchem.2003.09.006 
Rudge J. F., Maclennan J. and Stracke A. (2013) The geochemical consequences of mixing melts from a heterogeneous mantle. Geochim. Cosmochim. Acta 114, 112-143. doi:10.1016/j.gca.2013.03.042

Salters V. J. M. and Dick H. J. B. (2002) Mineralogy of the mid-ocean-ridge basalt source from neodymium isotopic composition of abyssal peridotites. Nature 418, 68-72. doi:10.1038/nature00798

Salters V. J. M. and Longhi J. (1999) Trace element partitioning during the initial stages of melting beneath mid-ocean ridges. Earth Planet. Sci. Lett. 166, 15-30. doi:10.1016/S0012-821X(98)00271-4

Salters V. J. M. and Stracke A. (2004) Composition of the depleted mantle. Geochem. Geophys. Geosyst. 5, Q05B07. doi:10.1029/2003GC000597

Salters V. J. M., Mallick S., Hart S. R., Langmuir C. H. and Stracke A. (2011) Domains of depleted mantle: new evidence from hafnium and neodymium isotopes. Geochem. Geophys. Geosyst. 12, Q08001. doi:10.1029/2011GC003617

Sanfillippo A., Salters V., Tribuzio R. and Zanetti A. (2019) Role of ancient, ultra-depleted mantle in mid-ocean-ridge magmatism. Earth Planet. Sci. Lett. 511, 89-98. doi:10.1016/j.eps1.2019.01.018

Shaw D. M. (1952) The geochemistry of thallium. Geochim. Cosmochim. Acta 2, 118-154. doi:10.1016/00167037(52)90003-3

Shu Y., Nielsen S. G., Zeng Z., Shinjo R., Blusztajn J., Wang X. and Chen S. (2017) Tracing subducted sediment inputs to the Ryukyu Arc-Okinawa Trough system: evidence from thallium isotopes. Geochim. Cosmochim. Acta 217, 462-491. doi:10.1016/j.gca.2017.08.035

Shu Y., Nielsen S. G., Marschall H. R., John T., Blusztajn J. and Auro M. (2019) Closing the loop: subducted eclogites match thallium isotope compositions of ocean island basalts. Geochim. Cosmochim. Acta 250, 130-148. doi:10.1016/j.gca.2019.02.004

Sims K. W. W. and DePaolo D. J. (1997) Inferences about mantle magma sources from incompatible element concentration ratios in oceanic basalts. Geochim. Cosmochim. Acta 61, 765-784. doi:10.1016/S00167037(96)00372-9

Sparks J. W. (1995) 7. Geochemistry of the lower sheeted dyke complex, Hole 504B, Leg 140. Proc. ODP Sci. Results 137, 81-97.

Stracke A. (2012) Earth's heterogeneous mantle: a product of convection-driven interaction between crust and mantle. Chem. Geol. 330-331, 274-299. doi:10.1016/j.chemgeo.2012.08.007

Stracke A. and Bourdon B. (2009) The importance of melt extraction for tracing mantle heterogeneity. Geochim. Cosmochim. Acta 73, 218-238. doi:10.1016/j.gca.2008.10.015

Stracke A., Bizimis M. and Salters V. J. M. (2003). Recycling oceanic crust: Quantitative constraints. Geochem. Geophys. Geosyst. 4, Q08003. doi:10.1029/2001GC000223

Stracke A., Hofmann A. W. and Hart S. R. (2005) FOZO, HIMU, and the rest of the mantle zoo. Geochem. Geophys. Geosyst. 6, Q05007. doi:10.1029/2004GC000824 
Stracke A., Snow J. E., Hellebrand E., von der Handt A., Bourdon B., Birbaun K. and Günther D. (2011) Abyssal peridotite Hf isotopes identify extreme mantle depletion. Earth Planet. Sci. Lett. 308, 359-368. doi:10.1016/j.epsl.2011.06.012

Stracke A., Genske F., Berndt J. and Koornneef J. M. (2019) Ubiquitous ultra-depleted domains in Earth's mantle. Nat. Geosci. 12, 851-855. doi:10.1038/s41561-019-0446-Z

Sun C. and Liang Y. (2012) Distribution of REE between clinopyroxene and basaltic melt along a mantle adiabat: effects of major elemnet composition, water, and temperature. Contrib. Mineral. Petrol. 163, 807-823. doi:10.1007/s00410-011-0700-x

Sun S.-s. and McDonough W. F. (1989) Chemical and isotopic systematics of oceanic basalts: implications for mantle composition and processes. In Magmatism in the Ocean Basins (eds. A. D. Saunders and M. J. Norry). Geological Soc., London, Special Publication. pp. 313-345. doi:10.1144/GSL.SP.1989.042.01.19

Teng F.-Z., Dauphas N. and Watkins J. M. (eds) (2017) Non-traditional stable isotopes. Rev. Mineral. Geochem. 82.

Uchimizu M. (1966) Geology and petrology of alkali rocks from Dogo, Oki Islands. J. Fac. Sci. Univ. Tokyo, Sec. 2 16, 85-159.

Vannucci R., Bottazzi B., Wulff-Pedersen E. and Neumann E.-R. (1998) Partitioning of REE, Y, Sr, Zr and Ti between clinopyroxene and silicate melts in the mantle under La Palma (Canary Islands): implications for the nature of the metasomatic agents. Earth Planet. Sci. Lett. 158, 39-51. doi:10.1016/S0012-821X(98)00040-5

Wang Z., Lazarov M., Steinmann L. K., Becker H., Zou Z. and Geng, X. (2018) The distribution of lead and thallium in mantle rocks: Insights from the Balmuccia peridotite massif (Italian Alps). Am. Mineral. 103, 1185-1199. doi:10.2138/am-2018-6423

Wasylenki L. E., Baker M. B., Kent A. J. R. and Stolper E. M. (2003) Near-solidus melting of the shallow upper mantle: partial melting experiments on depleted peridotite. J. Petrol. 44, 1163-1191. doi:10.1093/petrology/44.7.1163

Weaver B. L. (1991) The origin of ocean island basalt end-member compositions: trace element and isotopic constraints. Earth Planet. Sci. Lett. 104, 381-397. doi:10.1016/0012-821X(91)90217-6

Weis D. and Frey F. A. (1991) Isotope geochemistry of Ninetyeast Ridge basement basalts: Sr, Nd, and Pb evidence for involvement of the Kerguelen hot spot. Proc. ODP Sci. Results 121, 591-610. doi:10.2973/odp.proc.sr.121.170.1991

White W. B. (2015) Probing the Earth's deep interior through geochemistry. Geochem. Perspec. 4, 95-251.

Willbold M. and Stracke A. (2006) Trace element composition of mantle end-members: Implications for recycling of oceanic and upper and lower continental crust. Geochem. Geophys. Geosyst. 7, Q04004. doi:10.1029/2005GC001005

Willbold M. and Stracke A. (2010) Formation of enriched mantle components by recycling of upper and lower continental crust. Chem. Geol. 276, 188-197. doi:10.1016/j.chemgeo.2010.06.005

Wood B. J. and Kiseeva E. S. (2015) Trace element partitioning into sulfide: how lithophile elements become chalcophile and vice versa. Am. Mineral. 100 2371-2379. doi:10.2138/am-2015-5358CCBYNCND 
867 Wood B. J. and Trigila R. (2001) Experimental determination of aluminous clinopyroxene-melt partition coefficients 868 for potassic liquids, with application to the evolution of the Roman province potassic magmas. Chem. Geol. 172, 869 213-223. doi:10.1016/S0009-2541(00)00259-X

870 Workman R. K. and Hart S. R. (2005) Major and trace element composition of the depleted MORB mantle (DMM). $871 \quad$ Earth Planet. Sci. Lett. 231, 53-72. doi:10.1016/j.eps1.2004.12.005

872 Yang S., Humayun M. and Salters V. J. M. (2018) Elemental systematics in MORB glasses from the Mid-Atlantic 873 Ridge. Geochem. Geophys. Geosyst. 19, 4236-4259. doi:10.1029/2018GC007593

874 York D., Evensen N. M., Martínez M. L. and Delgado J. D. B. (2004) Unified equations for the slope, intercept, and 875 standard errors of the best straight line. Am. J. Phys. 72, 367-375. doi:10.1119/1.1632486

876 Zindler A. and Hart S. R, (1986) Chemical geodynamics. Annu. Rev. Earth Planet. Sci. 14, $493-571$.

877 Zuleger E., Alt J. C. and Erzinger J. (1996) Data report: Trace-element geochemistry of the lower sheeted dike 878 complex, Hole 504B, Leg 140. Proc. ODP Sci. Results 148 455-466. 


\section{Figure captions}

Figure 1: Plot of $\varepsilon^{205} \mathrm{Tl}$ against $\mathrm{Tl}$ concentration. There is no covariation. Large symbols: this study. Other data sources: [1] Blusztajn et al. (2018); [2] Prytulak et al. (2017); [3] Nielsen et al. (2007); [4] Nielsen et al. (2006a). * picrites.

Figure 2: Primitive Mantle-normalised trace element plots. Note that $\mathrm{Tl}$ appears twice (highlighted), positioned both between $\mathrm{Cs}$ and $\mathrm{Rb}$ (Prytulak et al., 2017) and between $\mathrm{La}$ and $\mathrm{Ce}$ (Jenner, 2017). The ordering otherwise follows that of Willbold and Stracke (2006). For almost all samples there is a clear negative $\mathrm{Tl}$ anomaly regardless of position, as emphasised by the averages for each end-member.

Figure 3: (a) $\mathrm{Ce} / \mathrm{Tl}$ and (b) $\mathrm{Tl}$ concentrations plotted against $\mathrm{MgO}$ contents. Thallium is a highly incompatible element, and consequently the absolute abundance co-varies with indices of melt differentiation, such as $\mathrm{MgO}$. However, $\mathrm{Ce} / \mathrm{Tl}$ ratios do not exhibit co-variation with melt evolution for OIB samples, indicating that $\mathrm{Ce}$ and $\mathrm{Tl}$ exhibit similar incompatibility with respect to magmatic processes in the mantle. Symbols and data sources as in Figure 1.

Figure 4: Plot of $\mathrm{Ce} / \mathrm{Tl}$ ratios versus $\mathrm{Tl}$ concentrations in oceanic basalts and subduction zone volcanics. $\mathrm{Ce} / \mathrm{Tl}$ trends clearly distinguish between tectonic melting regimes for fresh lavas. Note that Hawai ian and Icelandic picritic lavas (dark gray) lie off the general OIB trend to lower Tl concentrations, presumably due to the larger degree of melting they represent. Large symbols: this study. Other data sources (see Table 2, Electronic Annex 2): [1] Blusztajn et al. (2018); [2] Prytulak et al. (2017); [3] Nielsen et al. (2007); [4] Nielsen et al. (2006a); [5] Chauvel et al. (2012); [6] Nielsen et al (2016); [7] Nielsen et al. (2017a); [8] Prytulak et al. (2013); [9] Prytulak et al. (2017); [10] Shu et al. (2017); [11] Cox et al. (2019); [12] Jenner and O’Neill (2012); [13] Nielsen et al. (2014); [14] Yang et al. (2018). * picrites.

Figure 5: (a) MORB melting model of Nielsen et al. (2014), with $\mathrm{Tl}_{\mathrm{DM}}=0.48 \mathrm{ng} / \mathrm{g}, \mathrm{S}_{\mathrm{DM}}=195 \mu \mathrm{g} / \mathrm{g}$ and $\mathrm{D}^{\mathrm{Tl}}{ }_{\text {sulf } / \text { sil }}=36$ (for other parameters see Table 5). (b) Modified MORB melting model assuming $\mathrm{S}_{\mathrm{DM}}=100$ $\mu \mathrm{g} / \mathrm{g}$ and $\mathrm{D}^{\mathrm{Tl}}$ sulf/sil $=10$; lower $\mathrm{D}^{\mathrm{Tl}}{ }_{\text {sulf } / \text { sil }}$ increases the melt percentage required to achieve any given $\mathrm{Tl}-\mathrm{Ce} / \mathrm{Tl}$ data pair. In this modified model we permit variation of $\mathrm{D}^{\mathrm{Ce}}{ }_{\text {cpx/melt }}$ (see text, Table 5), reproducing both the average MORB Ce/Tl and the sense of variation. Best fit is achieved with a lower $\mathrm{Tl}_{\mathrm{DM}}$ of $0.27 \mathrm{ng} / \mathrm{g}$, implying a DM Ce/Tl of $\sim 1800$. (c) Modified model with variable $\mathrm{Tl}$ (see legend), $\mathrm{Ce}=0.55 \mu \mathrm{g} / \mathrm{g}, \mathrm{S}=100$ 
$\mu \mathrm{g} / \mathrm{g}, \mathrm{D}^{\mathrm{Tl}}$ sulf/sil $=10, \mathrm{D}^{\mathrm{Ce}}{ }_{\text {cpx/melt }}=0.1$ (d) Modified melting model with $\mathrm{Tl}=0.27 \mathrm{ng} / \mathrm{g}$, variable Ce (see legend; Workman and Hart, 2005), and other values as for subfigure (c). Symbols and data sources as in Figure 4. Figure 6: (a) Melting of PM (grey) and DM (black) sources (Table 6) with varying $\mathrm{D}^{\mathrm{Ce}}{ }_{\text {cpx/melt. }}$ (b) Melting of (i) a hypothetical mixed source with $\mathrm{Tl}=1 \mathrm{ng} / \mathrm{g}, \mathrm{Ce}=15 \mu \mathrm{g} / \mathrm{g}$, and $\mathrm{D}^{\mathrm{Ce}}{ }_{\mathrm{cpx} / \mathrm{melt}}=0.8$; and (ii) a hypothetical mixed source with $\mathrm{Tl}=0.5 \mathrm{ng} / \mathrm{g}, \mathrm{Ce}=5 \mu \mathrm{g} / \mathrm{g}$, and $\mathrm{D}^{\mathrm{Ce}}{ }_{\mathrm{cpx} / \mathrm{melt}}=0.15$. (c) $3-5 \%$ melting of a hypothetical source with $\mathrm{Ce}=5 \mu \mathrm{g} / \mathrm{g}$ and $\mathrm{D}_{\mathrm{cp} / \mathrm{melt}}^{\mathrm{Ce}}=0.1$. Source $\mathrm{Tl}$ concentration varies as indicated on figure. (d) As subfigure (c), but instead $\mathrm{Ce}=15 \mu \mathrm{g} / \mathrm{g}$ and $\mathrm{D}^{\mathrm{Ce}}{ }_{\text {ppx/melt }}=0.5$. Symbols and data sources as in Figure 4 . All displayed models assume $100 \mu \mathrm{g} / \mathrm{g} \mathrm{S}$ (Ding and Dasgupta, 2018) and $\mathrm{D}^{\mathrm{Tl}}{ }_{\text {sulf } / \text { sil }}=10$. All melting percentages as marked on subfigure (a).

Figure 7: Plots of $\varepsilon^{205} \mathrm{Tl}$ against (a) ${ }^{87} \mathrm{Sr} /{ }^{86} \mathrm{Sr}$, (b) ${ }^{143} \mathrm{Nd} /{ }^{144} \mathrm{Nd}$, (c) ${ }^{176} \mathrm{Hf} /{ }^{177} \mathrm{Hf}$, (d) ${ }^{206} \mathrm{~Pb} /{ }^{204} \mathrm{~Pb}$, (e) ${ }^{207} \mathrm{~Pb} /{ }^{204} \mathrm{~Pb}$, (f) ${ }^{208} \mathrm{~Pb} /{ }^{204} \mathrm{~Pb}$. For OIB samples, there is no co-variation of $\varepsilon^{205} \mathrm{Tl}$ and the radiogenic isotope systems commonly used to define mantle components, with the possible exception of ${ }^{143} \mathrm{Nd} /{ }^{144} \mathrm{Nd}$ in Icelandic picrites. Error bars are generally smaller than symbols. Symbols and data sources as in Figure 4.

Figure 8: Plots of ratios employed to track AOC contributions to OIB source against $\varepsilon^{205} \mathrm{Tl}$. (a) $\mathrm{Ce} / \mathrm{Tl}$ against $\varepsilon^{205} \mathrm{Tl}$, showing literature main-phase St Helena lavas and St Helena samples from this study, (b) Ce/Tl against $\varepsilon^{205} \mathrm{Tl}$ for all OIB samples, (c) Ce/Pb against $\varepsilon^{205} \mathrm{Tl}$ with the same samples as subfigure (a), (d) $\mathrm{Ce} / \mathrm{Pb}$ against $\varepsilon^{205} \mathrm{Tl}$ for all OIB samples. Blusztajn et al. (2018) argued that a sense of correlation for main-phase St Helena lavas indicated a role for subduction-processed AOC in generating the HIMU array. However, this trend is not replicated in HIMU lavas from other localities, and is not unique to HIMU-type lavas. Symbols and data sources as in Figure 4.

Figure 9: Plot of $\varepsilon^{205} \mathrm{Tl}$ against $\mathrm{Tl} / \mathrm{Tl} 1^{*}$ ratios. Tl* = Brett_etal_GCA_Eqn1.pdf or Brett_etal_GCA_Eqn2.pdf, where N denotes concentration values normalised to PM (a,c), or DM (b,d). Relative to Cs and $\mathrm{Rb}, \mathrm{Tl} / \mathrm{Tl} l^{*}$ values $>0.5$ (for both PM and DM normalisations) are associated with $\mathrm{Tl}$ isotopic compositions that are distinct from the mantle range (green band). Relative to La and Ce, it is less clear whether there is any association. Symbols and data sources as in Figure 4.

Figure A1: $\mathrm{D}^{\mathrm{Ce}}{ }_{\text {cpx/melt }}$ values versus $\mathrm{CaO}$ in clinopyroxene. This illustrative plot has not been corrected for pressure and temperature, or for other compositional variables including degree of hydration. With the notable exception of Green et al. (2000) and the two McDade studies, which examine melting under strongly 
934 hydrous conditions, there is a general sense of increasing $\mathrm{Ce}$ compatibility as $\mathrm{CaO}$ in cpx increases both 935 within and between studies. 
937 Table 1. Summary of OIB localities with published Tl concentration and isotopic composition data.

\begin{tabular}{|c|c|c|c|c|c|c|c|c|c|}
\hline \multirow[b]{2}{*}{ Locality } & \multicolumn{2}{|c|}{ FOZO/PREMA } & \multicolumn{2}{|c|}{ EMI } & \multicolumn{2}{|l|}{ EM } & \multicolumn{3}{|c|}{ HIMU } \\
\hline & Hawai i & Iceland & Gough & Tristan & Marquesas $^{\dagger}$ & Azores & St Helena & Rurutu & Tubuai \\
\hline literature $[\mathrm{Tl}]$ & $\mathrm{x}$ & $\mathrm{x}$ & & & $\mathrm{x}$ & $\mathrm{x}$ & $\mathrm{x}$ & & \\
\hline literature $\varepsilon^{205} \mathrm{Tl}$ & $\mathrm{x}$ & $\mathrm{x}$ & & & & $\mathrm{x}$ & $\mathrm{x}$ & & \\
\hline${ }^{87} \mathrm{Sr} /{ }^{86} \mathrm{Sr}$ & o & range & $\mathrm{x}$ & $\mathrm{x}$ & $\mathrm{x}$ & $\mathrm{x}$ & $\mathrm{x}$ & $\mathrm{x}$ & $\mathrm{x}$ \\
\hline${ }^{143} \mathrm{Nd} /{ }^{144} \mathrm{Nd}$ & o & $\mathrm{x}$ & $\mathrm{x}$ & $\mathrm{x}$ & $\mathrm{x}$ & $\mathrm{x}$ & $\mathrm{x}$ & $\mathrm{x}$ & $\mathrm{x}$ \\
\hline${ }^{176} \mathrm{Hf} /{ }^{177} \mathrm{Hf}$ & & range & $\mathrm{x}$ & $\mathrm{x}$ & $\mathrm{x}$ & & $\mathrm{x}$ & & o \\
\hline $\mathrm{Pb}$ isotopes & $\mathrm{x}$ & range & & & $\mathrm{x}$ & $\mathrm{x}$ & $\mathrm{x}$ & $\mathrm{x}$ & $\mathrm{x}$ \\
\hline this study & & & $\mathrm{x}$ & $\mathrm{x}$ & $\mathrm{x}$ & & $\mathrm{x}$ & $\mathrm{x}$ & $\mathrm{x}$ \\
\hline key references & $1 *$ & $2 *, 3$ & 4,5 & 4,5 & 6 & 2 & $4,5,7$ & 8 & 9 \\
\hline
\end{tabular}

$939 *$ picrites.

$940 \uparrow$ Note that Marquesas lavas exhibit variable composition covering a very wide range of radiogenic isotopic 941 compositions.

$942 \mathrm{x}=$ data exists; $\mathrm{o}=$ partial data; range $=$ a range is known, but samples have not been individually analysed.

943 [1] Nielsen et al. (2006a); [2] Nielsen et al. (2007); [3] Prytulak et al. (2017); [4] Willbold and Stracke

944 (2006); [5] Willbold and Stracke (2010); [6] Chauvel et al. (2012); [7] Blusztajn et al. (2018); [8] Chauvel et 945 al. (1997); [9] Chauvel et al. (1992). 
946 Table 2. Key geochemical data for OIB samples analysed in this study.

\begin{tabular}{|c|c|c|c|c|c|c|c|c|}
\hline \multirow{2}{*}{\multicolumn{9}{|c|}{ MgO* (wt\%) Ce ( $\mu \mathrm{g} / \mathrm{g}) \quad \mathrm{Tl}(\mathrm{ng} / \mathrm{g})$}} \\
\hline & & & & & & & & \\
\hline G6 & 7.94 & 101 & 26 & 3915 & 0.5 & 2.2 & 2 & $3(1 N U+2 N U I I)$ \\
\hline G102 & 5.28 & 107 & 76 & 1402 & -2.5 & 0.6 & 2 & 3 \\
\hline G117 & 4.52 & 113 & 39 & 2921 & 3.8 & 0.6 & 1 & 4 \\
\hline G118 & 12.97 & 73.9 & 49 & 1495 & -0.6 & 0.5 & 1 & 2 \\
\hline G132 & 5.04 & 87.1 & 95 & 919 & -4.6 & 0.5 & 1 & 3 \\
\hline G135 & 5.85 & 112 & 53 & 2104 & -0.6 & 0.5 & 1 & 2 \\
\hline $\begin{array}{l}\text { B167 } \\
\text { Tristan da Cunha } \\
\text { (EMI) }\end{array}$ & 3.39 & 107 & 74 & 1437 & -3.2 & 0.5 & 1 & 1 \\
\hline T16 & 4.74 & 134 & 101 & 1321 & -2.3 & 0.5 & 1 & 2 \\
\hline T60 & 12.2 & 60.9 & 38 & 1600 & -0.3 & 0.5 & 1 & 2 \\
\hline T64 & 8.91 & 115 & 64 & 1796 & -1.1 & 0.5 & 1 & 1 \\
\hline T122 & 7.28 & 104 & 55 & 1888 & -1.2 & 0.5 & 1 & 2 \\
\hline T497 & 7.61 & 136 & 87 & 1559 & -1.2 & 0.8 & 2 & 9 \\
\hline T557 & 8 & 112 & 56 & 2006 & -1.2 & 1.5 & 2 & 7 \\
\hline $\begin{array}{l}\text { T557 (leached) } \\
\text { Fatu Hiva, } \\
\text { Marquesas (EM }\end{array}$ & & & & & -1.6 & 0.9 & 1 & $1(N U I I)$ \\
\hline FH01 & 10.6 & 110 & 7 & 16740 & 0.0 & 1.3 & 1 & 1 \\
\hline FH11 & 6.8 & 99.0 & 26 & 3837 & -3.6 & 0.8 & 2 & 3 \\
\hline $\begin{array}{l}\text { FH18 } \\
\text { Hiva Oa, } \\
\text { Marquesas }\left(\text { EM }^{\dagger}\right.\end{array}$ & 12.2 & 81.5 & 32 & 2554 & -1.8 & 0.5 & 1 & 1 \\
\hline HV64 & 8 & 81.1 & 17 & 4649 & 0.7 & 0.5 & 1 & 1 \\
\hline $\begin{array}{l}\text { HV76 } \\
\text { Montane, } \\
\text { Marquesas }\left(\text { EM }^{\dagger}\right.\end{array}$ & 5.14 & 72.7 & 63 & 1162 & -0.3 & 0.7 & 1 & 2 \\
\hline MT04 & 5.63 & 71.6 & 18 & 3996 & -3.9 & 1.0 & 3 & $3(2 N U+1 N U I I)$ \\
\hline $\begin{array}{l}\text { MT08 } \\
\text { Tahuata, } \\
\text { Marquesas }\left(\text { EM }^{\dagger}\right.\end{array}$ & 5.53 & 82.0 & 25 & 3224 & 0.6 & 0.5 & 2 & 2 \\
\hline TH4 & 6.37 & 108 & 77 & 1415 & -2.9 & 0.5 & 1 & 1 \\
\hline TH5 & 7.44 & 137 & 66 & 2064 & -0.5 & 0.5 & 1 & 2 \\
\hline TH8 & 4.67 & 96.3 & 24 & 4045 & 1.0 & 0.5 & 1 & 1 \\
\hline TH8 (leached) & & & & & 2.2 & 0.9 & 1 & 1 (NUII) \\
\hline TH13 & 6.09 & 80.7 & 15 & 5482 & -3.5 & 0.6 & 2 & 4 \\
\hline TH14 & 8.37 & 109 & 177 & 614 & -6.4 & 0.5 & 1 & 4 \\
\hline TH18 & 6.4 & 87.6 & 43 & 2014 & 0.4 & 1.2 & 2 & $3(2 N U+1 N U I I)$ \\
\hline TH18 (leached) & & & & & -0.2 & 0.8 & 1 & $l(N u I I)$ \\
\hline TH31 & 5.6 & 82.1 & 18 & 4574 & -1.9 & 1.1 & 2 & $2(1 N U+1 N U I I)$ \\
\hline $\begin{array}{l}\text { TH39 } \\
\text { Ua Huka, } \\
\text { Marquesas }\left(\text { EM }^{\dagger}\right.\end{array}$ & 9.2 & 81.5 & 18 & 4533 & 4.4 & 0.9 & 1 & 1 \\
\hline UH53 & 0.38 & 155 & 235 & 663 & -1.8 & 0.5 & 1 & 4 \\
\hline UH81 & 7.75 & 90.4 & 121 & 748 & -1.9 & 0.5 & 2 & 5 \\
\hline UH89 & 7.2 & 89.8 & 39 & 2278 & -3.5 & 0.5 & 1 & 3 \\
\hline UH93 & 9.85 & 72.8 & 97 & 753 & -1.2 & 0.5 & 2 & 3 \\
\hline
\end{tabular}




\begin{tabular}{|c|c|c|c|c|c|c|c|c|}
\hline $\mathrm{H} 28$ & 6.64 & 101 & 26 & 3936 & -0.9 & 0.5 & 1 & 5 \\
\hline H38 & 15.87 & 41.3 & 40 & 1043 & -3.1 & 0.5 & 1 & 2 \\
\hline H64 & 10.97 & 61.7 & 14 & 4360 & -0.7 & 0.5 & 1 & 2 \\
\hline $\begin{array}{l}\text { H69 } \\
\text { Rurutu, Austral- } \\
\text { Cook (HIMU) }\end{array}$ & 9.09 & 62.8 & 94 & 665 & -3.3 & 0.9 & 2 & 9 \\
\hline RRT032 & 6.02 & 47.9 & 45 & 1073 & -6.4 & 1.3 & 2 & 4 \\
\hline RRT037 & 7.4 & 59.8 & 40 & 1489 & 6.6 & 0.5 & 1 & 1 \\
\hline RRT037 (leached) & & & & & 4.9 & 0.9 & 1 & $1(N U I I)$ \\
\hline $74-386$ & 7.24 & 56.5 & 14 & 4024 & -2.3 & 0.5 & 2 & 2 \\
\hline $74-390$ & 6.29 & 74.9 & 44 & 1709 & -6.3 & 0.5 & 1 & 1 \\
\hline 74-390 (leached) & & & & & -3.7 & 0.9 & 1 & $1(N U I I)$ \\
\hline $\begin{array}{l}74-396 \\
\text { Tubuai, Austral- } \\
\text { Cook }(\text { HIMU })\end{array}$ & 7.89 & 73.9 & 32 & 2290 & -3.4 & 0.5 & 1 & 3 \\
\hline TBA9 & 17.9 & 96.4 & 18 & 5371 & -2.1 & 1.2 & 1 & 2 (NUII) \\
\hline K109 & 15.5 & 117 & 19 & 6108 & -5.9 & 0.5 & 1 & 1 \\
\hline 108B & 10.85 & 88.4 & 10 & 9069 & -3.1 & 0.5 & 1 & 2 \\
\hline 5433 & 6.2 & 145 & 31 & 4691 & -0.3 & 0.5 & 1 & 2 \\
\hline 5434 & 11.26 & 84.0 & 25 & 3393 & -3.5 & 0.5 & 1 & 2 \\
\hline 5435 & 4.85 & 226 & 50 & 4497 & -4.8 & 2.4 & 2 & $3(1 \mathrm{NU}+2 \mathrm{NUII})$ \\
\hline 5436 & 9.59 & 111 & 12 & 9279 & -2.1 & 0.5 & 1 & 1 \\
\hline
\end{tabular}

$949 *$ MgO values per Table 1 and references therein (see Electronic Annex $2 \mathrm{~b}$ for full details)

$950 †$ Marquesas lavas exhibit variable composition: at a given ${ }^{87} \mathrm{Sr} /{ }^{86} \mathrm{Sr}$ value, lavas from the 'Ua Huka' group

951 (Ua Huka, young Hiva $\mathrm{Oa}$ ) have higher $\mathrm{Nd}$ isotopic compositions, and lavas from the 'Fatu Hiva' group

952 (Fatu Hiva, old Hiva Oa, Montane, Tahuata) have higher ${ }^{206} \mathrm{~Pb} /{ }^{204} \mathrm{~Pb}$ (see Chauvel et al., 2012; Electronic

953 Annex 2).

9542 sd is quoted as the highest of (1) the uncertainty for repeat analyses of BCR-2 on the $N u H R$, (2) the 955 uncertainty for repeated measurements of the Aldrich Tl solution on the Nu Plasma II, or (3) the uncertainty 956 for repeat analyses of a given sample. 
957 Table 3. Slopes obtained for York regressions (York et al., 2004) between $\log [\mathrm{Tl}]$ and $\log [$ Element] (see 958 text). For MORB, $n=909$ except Cs, for which $n=702$. For OIB, $n=48$.

959

\begin{tabular}{lcccc}
\hline & \multicolumn{2}{c}{ MORB } & \multicolumn{2}{c}{ OIB } \\
Element & slope & 2sd & slope & 2sd \\
\hline $\mathrm{Ce}$ & 0.994 & 0.030 & 0.102 & 0.122 \\
$\mathrm{Cs}$ & 2.608 & & 2.033 & 0.571 \\
$\mathrm{La}$ & 1.285 & 0.047 & 0.116 & 0.136 \\
$\mathrm{~Pb}$ & 0.875 & 0.021 & 1.131 & 0.488 \\
$\mathrm{Rb}$ & 3.114 & 0.218 & 1.091 & 0.504 \\
\hline
\end{tabular}

960 
961 Table 4. Modal mineralogy and reaction coefficients used in melting models.

962

\begin{tabular}{|c|c|c|c|c|}
\hline \multirow[b]{2}{*}{ mineral } & \multicolumn{2}{|c|}{ spinel lherzolite $(\mathrm{MORB})$} & \multicolumn{2}{|c|}{ garnet lherzolite $(\mathrm{OIB})$} \\
\hline & vol proportion $(\%)^{1}$ & melting coefficient $^{2}$ & vol proportion $(\%)^{3}$ & melting coefficient $^{3}$ \\
\hline olivine & 0.57 & -0.2 & 0.55 & 0.08 \\
\hline clinopyroxene & 0.13 & 0.8 & 0.25 & 0.81 \\
\hline orthopyroxene & 0.28 & 0.32 & 0.15 & -0.19 \\
\hline spinel & 0.02 & 0.08 & - & - \\
\hline garnet & - & - & 0.05 & 0.3 \\
\hline sulphide & variable & SCSS* & variable & SCSS \\
\hline
\end{tabular}

963

964 * Sulphur concentration at sulphide saturation for basaltic melts (Liu et al., 2007; Mavrogenes and O'Neill, 965 1999; O’Neill and Mavrogenes, 2002). [1] Workman and Hart (2005); [2] Baker and Stolper (1994) and 966 Wasylenki et al. (2003), as modified by Nielsen et al. (2014); [3] Elliott et al. (2007). 
Table 5. Parameters used in models of MORB and OIB melting.

968

\begin{tabular}{|c|c|c|c|c|c|c|c|}
\hline \multirow[b]{2}{*}{ Variable } & \multirow[b]{2}{*}{ Symbol } & \multicolumn{2}{|c|}{ Nielsen et al. 2014 (MORB) } & \multicolumn{2}{|c|}{ MORB } & \multicolumn{2}{|c|}{$O I B$} \\
\hline & & Value range & References & Value range & References & Value range & References \\
\hline Melting & & & & & & & \\
\hline melt fraction & $\mathrm{F}$ & $0-16 \%$ & - & $0-16 \%$ & - & $0-18 \%$ & - \\
\hline melt increment & & $0.01 \%$ & - & $0.1 \%$ & - & $0.1 \%$ & - \\
\hline pressure (avg) & & $1.5 \mathrm{GPa}$ & - & $1.5 \mathrm{GPa}$ & - & $3 \mathrm{GPa}$ & - \\
\hline temperature (avg) & & $1350{ }^{\circ} \mathrm{C}$ & - & $1350{ }^{\circ} \mathrm{C}$ & - & $1445{ }^{\circ} \mathrm{C}$ & - \\
\hline $\mathrm{FeO}$ in melt & & $\sim 10 \%$ & 8 & $\sim 10 \%$ & 8 & $\sim 10 \%$ & sample data \\
\hline SCSS & & $1200 \mu \mathrm{g} / \mathrm{g}$ & $9-11$ & $1200 \mu \mathrm{g} / \mathrm{g}$ & $9-11$ & $1200 \mu \mathrm{g} / \mathrm{g}$ & $9-11$ \\
\hline
\end{tabular}

Partition coefficients

Thallium

$\begin{array}{lc}\mathrm{D}_{\text {cpx/melt }} & 0.0006 \\ \mathrm{D}_{\text {opx/melt }} & 0.00045 \\ \mathrm{D}_{\text {ol/melt }} & 4.5 \times 10^{-5} \\ \mathrm{D}_{\text {sp/melt }} & 0 \\ \mathrm{D}_{\mathrm{g} / \text { melt }} & - \\ \mathrm{D}_{\text {sulf/melt }} & 18-100\end{array}$

1

0.0006

1

0.0006

1

$1 \quad 0.00045$

1

$$
0.00045
$$

$4.5 \times 10^{-5}$

1

1

1

Bulk D

$0.0002-0.11$

model

0

$D_{\text {cpx/melt }}$

0.14

$\mathrm{D}_{\text {opx/melt }}$

0.006

$D_{\text {ol } / \text { melt }}$

$4 \times 10^{-5}$

$D_{\text {sp/melt }}$

0

$D_{\text {gt/melt }}$

-

$D_{\text {sulf } / \text { melt }}$

0

Bulk D

0.02

2
2
2
assumed
-
assumed

$$
\text { 1-25 }
$$

1

[1] Assumed identical to Rb partition coefficients of Donnelly et al. (2004); [2] McDade et al. (2003a); [3] Adam and Green (2006) were unable to determine a partition coefficient for Tl between garnet and silicate melt, but for LILE values were very low; [4] Frey (1969); [5] Irving and Frey (1984); [6] Nagasawa et al. (1969); [7] Matsui et al. (1977); [8] Gale et al. (2013); [9] Liu et al. (2007); [10] Mavrogenes and O'Neill (1999); [11] O’Neill and Mavrogenes (2002). 
975 Table 6. Estimated Ce, S and Tl concentrations in potential contributions to OIB source regions.

976

\begin{tabular}{|c|c|c|c|c|c|c|}
\hline Reservoirs & $\mathrm{Ce}(\mu \mathrm{g} / \mathrm{g})$ & References & Tl (ng/g) & References & $S(\mu g / g) *$ & References \\
\hline $\mathrm{DM}$ & 0.55 & 1 & $0.27-0.48$ & 9; model & $0-400$ & 2; model \\
\hline $\mathrm{PM}$ & 1.675 & 2 & 3.5 & 2 & $0-400$ & 2; model \\
\hline $\begin{array}{l}\text { Peridotites } \\
\text { FeMn sediment } \\
\text { (hydrogenetic) }\end{array}$ & $0.020-0.39$ & 3 & $0.05-3.5$ & 11 & $76-360$ & 3,12 \\
\hline $\begin{array}{l}\text { Subducted eclogites } \dagger \\
\text { Subduction-processed } \\
\text { oceanic crust }\end{array}$ & $20(1-210)$ & $\begin{array}{l}13 \\
\text { calculated }\end{array}$ & $60(2-350)$ & $\begin{array}{c}13 \\
\text { calculated }\end{array}$ & - & - \\
\hline
\end{tabular}

977

978

979

980

981

982

* Sulphide abundance was converted to $\mathrm{S}$ concentration using the assumption that on average mantle sulphides are $36 \mathrm{wt} \% \mathrm{~S}$, i.e. dominantly FeNi sulphides. † mean (range). [1] Workman and Hart (2005); [2] McDonough and Sun (1995); [3] Wang et al. (2018); [4] Sparks (1995); [5] Zuleger et al. (1996); [6] Bach et al. (1996); [7] Sun and McDonough (1989); [8] Piper (1974); [9] Nielsen et al. (2014); [10] Nielsen et al. (2006b); [11] Rehkämper et al. (2002); [12] Ding and Dasgupta (2018); [13] Shu et al. (2019). 


\section{Supplementary Figures}

984

Figure S1: Plot of $\varepsilon^{205} \mathrm{Tl}$ against $\mathrm{MgO}$ content for samples of this study and from the literature. $\varepsilon^{205} \mathrm{Tl}$ does not vary systematically with melt evolution. As the majority of samples are not cogenetic, two suites of lavas following common liquid lines of descent (Hekla, Iceland; Anatahan, Marianas) are highlighted, showing that even at low $\mathrm{MgO}$ there is no correlation with $\varepsilon^{205} \mathrm{Tl}$. Approximate fields of fractionating phases are indicated. Data sources: [1] Prytulak et al. (2017); [2] Blusztajn et al. (2018); [3] Nielsen et al. (2007); [4] Nielsen et al. (2006a). * picrites.

Figure S2: Depleted Mantle-normalised trace element plots. Here the negative Tl anomaly, while still present on average, is less pronounced - particularly for EM-type lavas.

Figure S3: Tl anomaly exhibits clearer covariation with absolute $\mathrm{Tl}$ abundance when calculated relative to REE than when calculated relative to LILE (with the possible exception of HIMU). Symbols and data sources as in Figure 5.

Figure S4: $\mathrm{Plot}$ of $\mathrm{La} / \mathrm{Tl}, \mathrm{Pb} / \mathrm{Tl}, \mathrm{Rb} / \mathrm{Tl}$ and $\mathrm{Cs} / \mathrm{Tl}$ ratios against $\mathrm{Tl}$ concentration. Only the $\mathrm{La} / \mathrm{Tl}$ ratios distinguishes tectonic settings as clearly as the Ce/Tl ratios. Symbols and data sources as in Figure 5.

Figure S5: Process identification plot (Minster and Allègre, 1978) of Tl/Ce against 1/Tl. Also shown are melting patterns (melt fraction $\mathrm{F}=0.0001$ to 1 ) for $\mathrm{DM}(\mathrm{Tl}=0.00038 \mu \mathrm{g} / \mathrm{g}, \mathrm{Ce}=0.772 \mu \mathrm{g} / \mathrm{g})$ and $\mathrm{PM}(\mathrm{Tl}=$ $0.0035 \mu \mathrm{g} / \mathrm{g}, \mathrm{Ce}=1.675 \mu \mathrm{g} / \mathrm{g}$ ), in addition to the fractional crystallisation trend ( $\mathrm{F}=1$ to 0.1 ), assuming bulk $\mathrm{D}_{\mathrm{Tl}}=0.02$ and bulk $\mathrm{D}_{\mathrm{Ce}}=0.06$. While most of the variation in OIB is subparallel to the DM melting trend, with scatter leaving room for some fractional crystallisation, the observed range significantly exceeds that which can be explained simply through a combination of melting and fractional crystallisation. The OIB trend therefore requires mixing melts from different sources, one of which cannot contain more than negligible $\mathrm{Tl}$ (note y-intercept of trend). Symbols and data sources as in Figure 5.

Figure S6: Mixing between St Helena HIMU average composition (Blusztajn et al., 2018) and three "AOC" values (see Table S1). Ticks correspond to admixture of 10\%, 20\% and 30\% of AOC as labelled for ODP 504B.

\begin{tabular}{llllll}
\hline & \multicolumn{1}{c}{ DM } & $\begin{array}{c}\text { St Helena } \\
\text { average }\end{array}$ & $\begin{array}{c}\text { ODP 504B } \\
(\sim 6.6 \mathrm{Ma})\end{array}$ & $\begin{array}{c}\text { DSDP 417/418 } \\
(\sim 109 \mathrm{Ma})\end{array}$ & "Modern AOC" \\
\hline $\mathrm{Tl}(\mu \mathrm{g} / \mathrm{g})$ & 0.00038 & 0.03 & 0.25 & 0.07 & $\underline{0.017}$ \\
$\mathrm{Ce}(\mu \mathrm{g} / \mathrm{g})$ & 0.772 & 80.83 & 4.31 & 6.19 & $\underline{\underline{12}}$ \\
$\mathrm{~Pb}(\mu \mathrm{g} / \mathrm{g})$ & 0.0232 & 2.06 & 0.36 & 0.69 & $\underline{0.6}$ \\
$\mathrm{Ce} / \mathrm{Pb}$ & 33 & $\sim 40$ & 12 & 9 & 20 \\
$\varepsilon^{205} \mathrm{Tl}$ & -2 & $\sim-2$ & -15 & -5.4 & -15 \\
\hline
\end{tabular}

Table S1. For DM, values are taken from Salters and Stracke (2004), except $\varepsilon^{205} \mathrm{Tl}$ (Nielsen et al., 2006a). For DSDP 417/418, supercomposite values are taken from Blusztajn et al. (2018) and Staudigel et al. (1995). ODP 504B values are taken from Nielsen et al. (2006b) and Bach et al. (2003). "Modern AOC" values are 
1012 taken from Blusztajn et al. (2018) or inferred (underlined). St Helena average values are as reported by $10 \mathrm{M}$ 

Figure 3

O EMI (Gough, Tristan) o St Helena [1]

O EM (Marquesas)

- Iceland [2]

O HIMU (St Helena,

Rurutu, Tubuai)

- Azores [3]

- *Iceland [3]

- *Hawai'i [4]

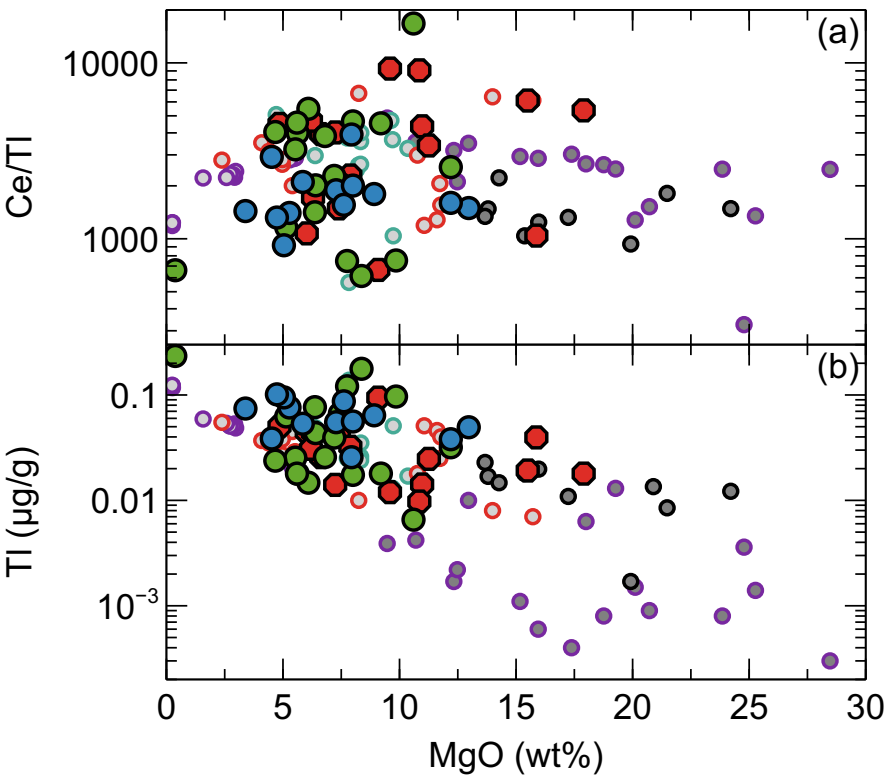


Figure 6
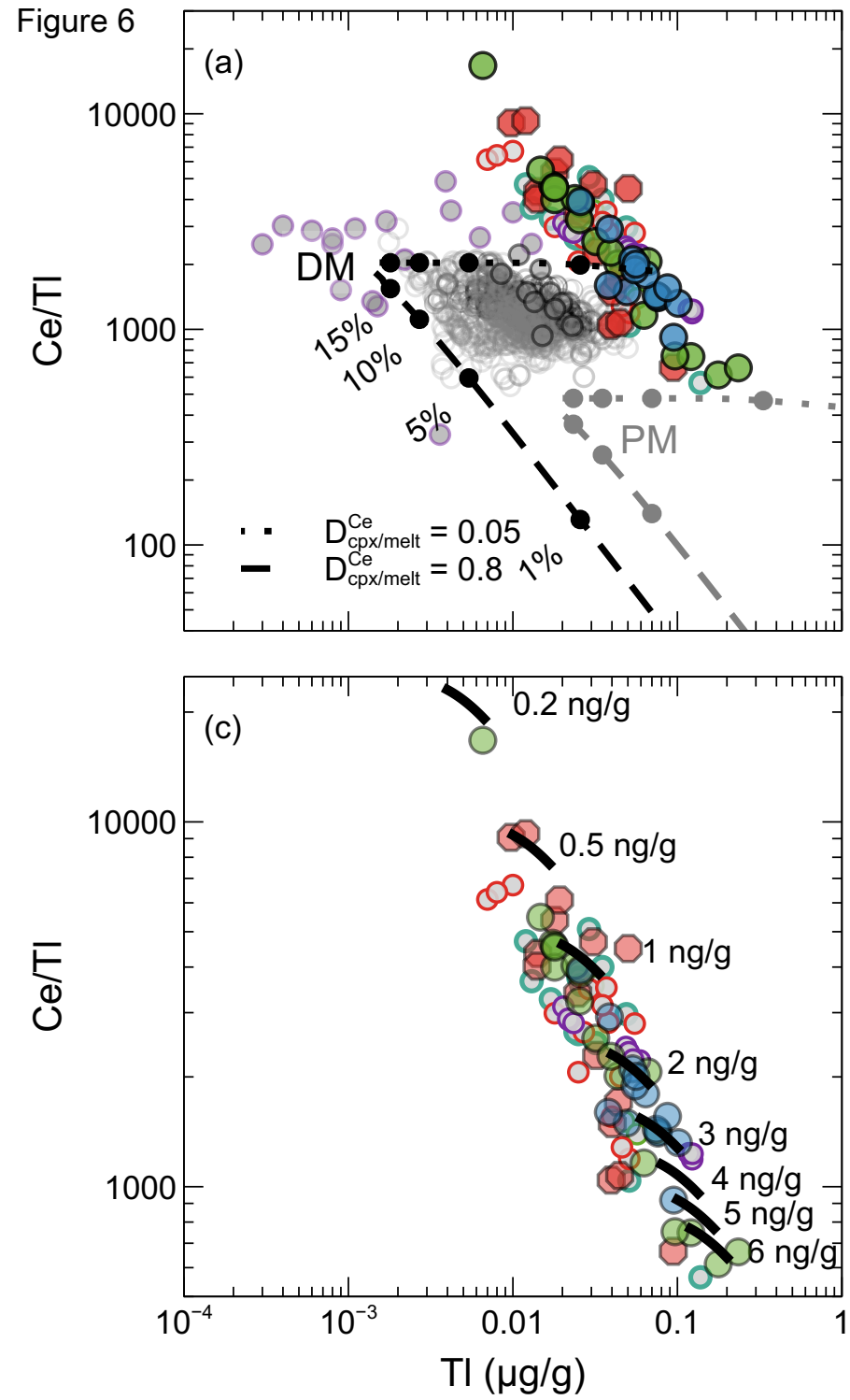
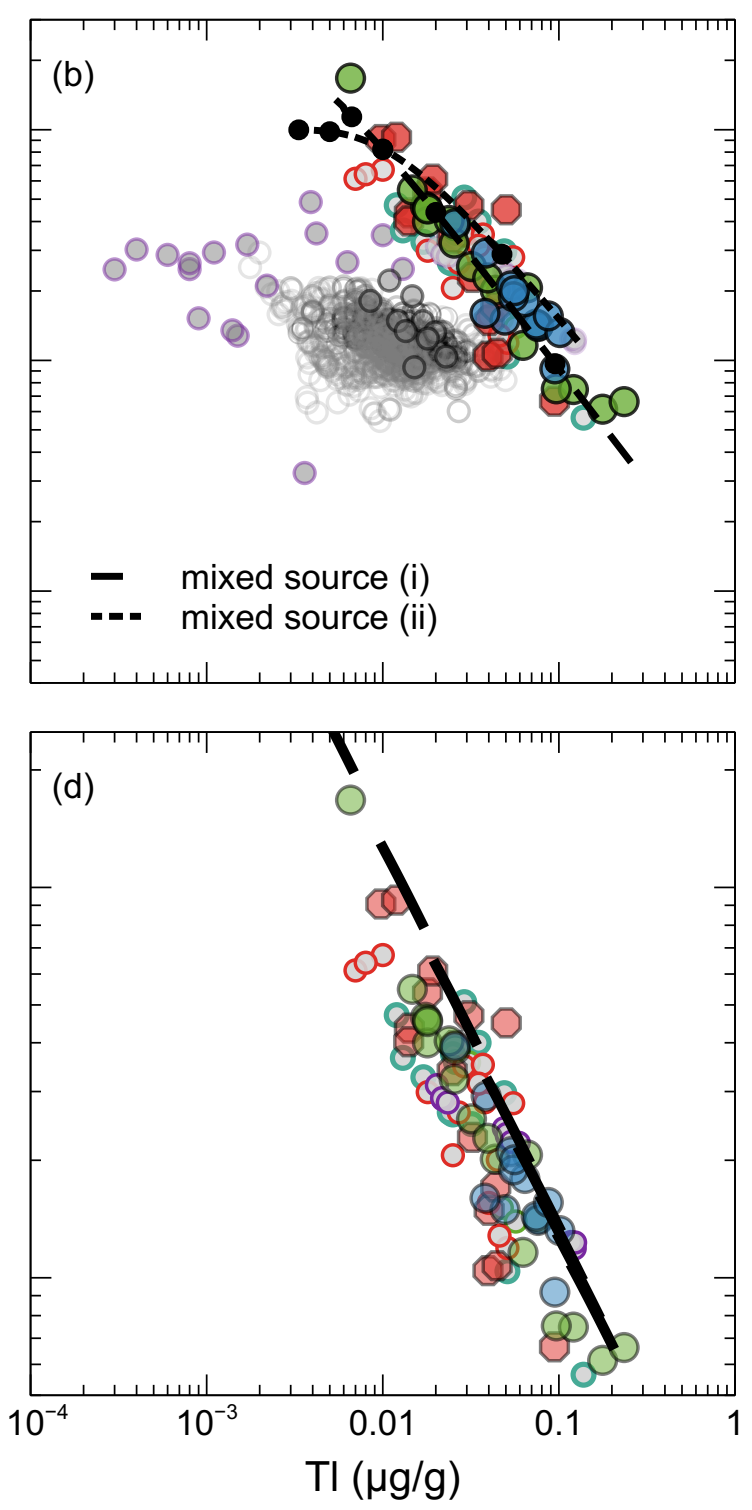

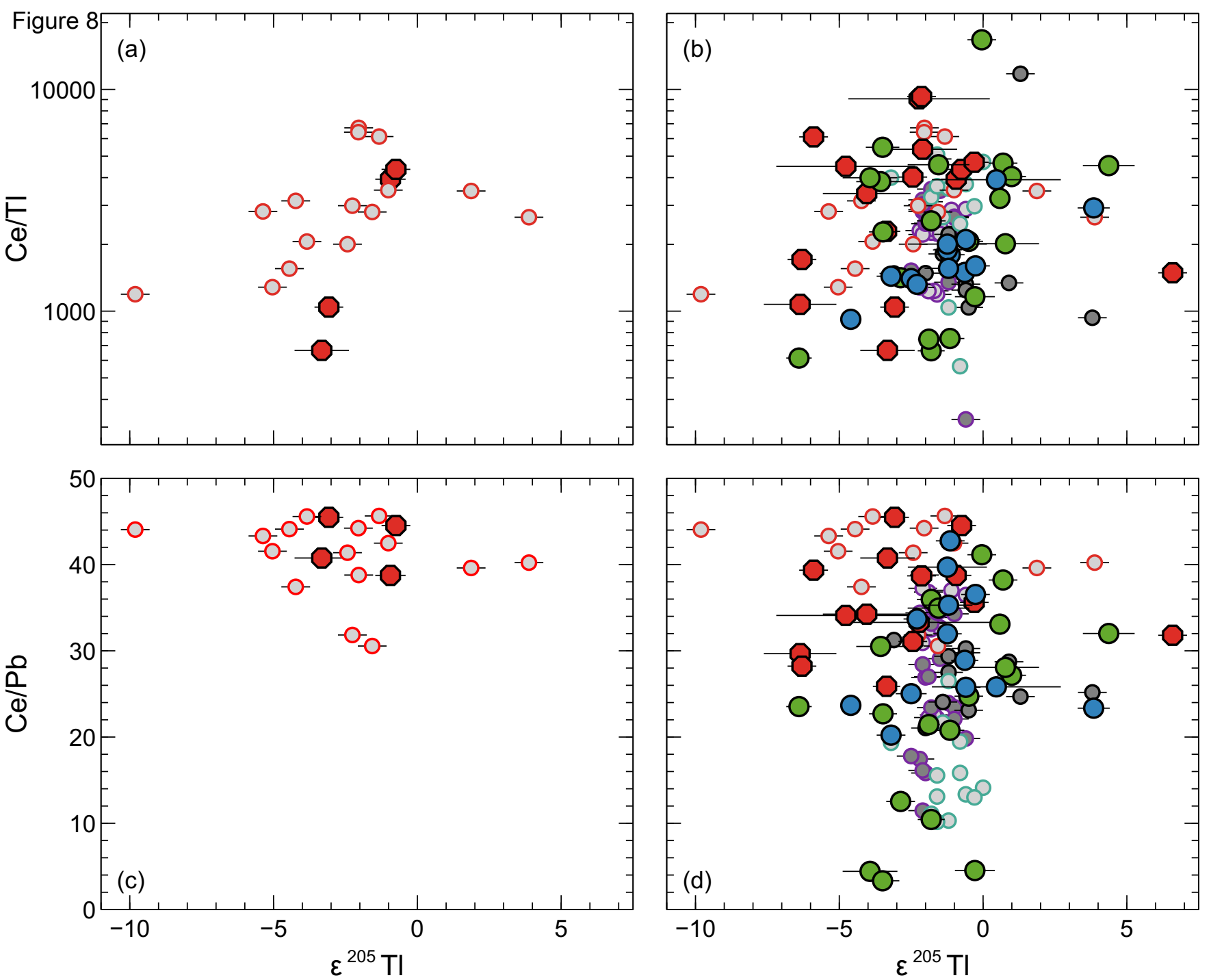


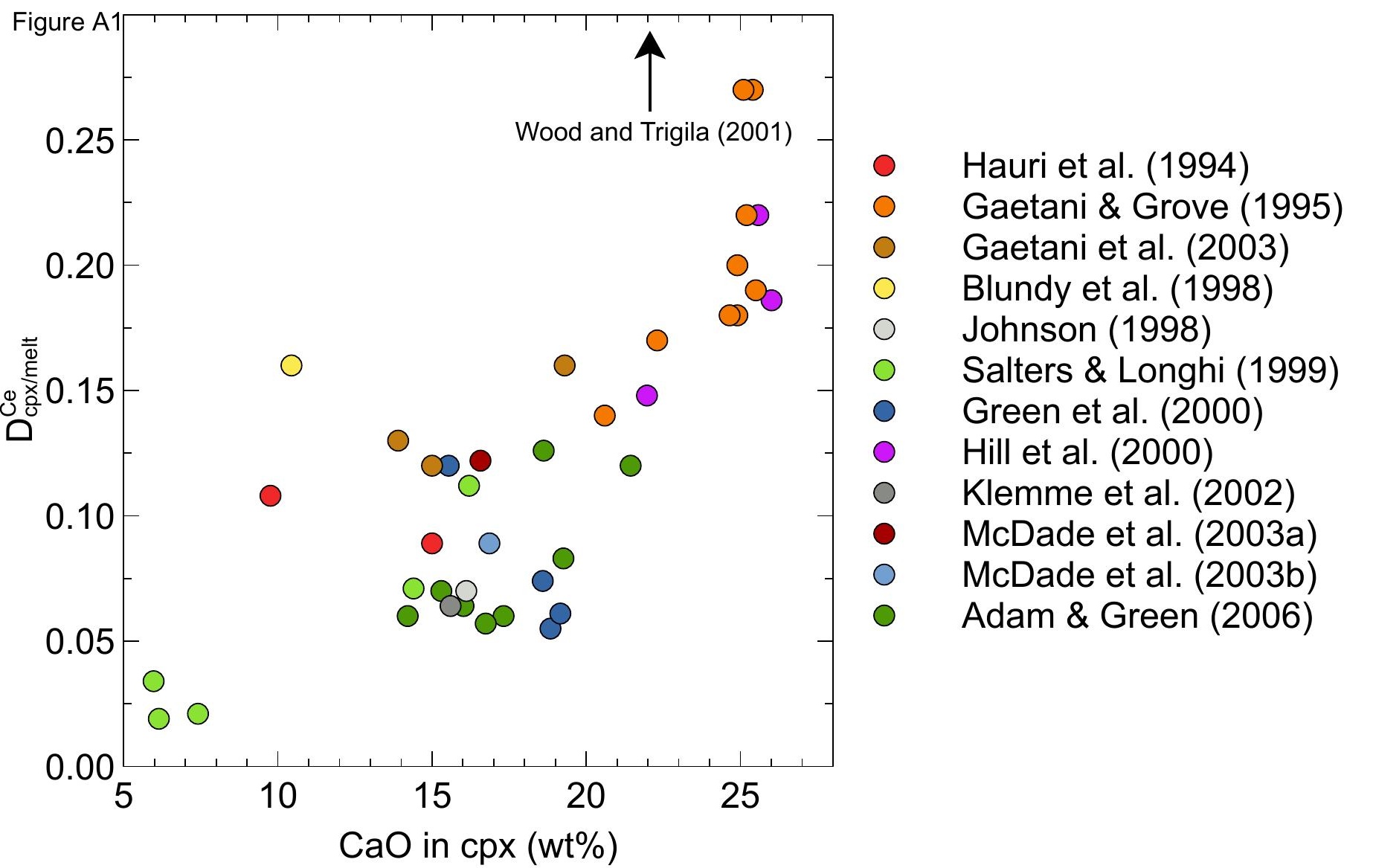


Figure Sb Hekla [1]

Anatahan [1]

- EMI (Gough, Tristan)

- EM (Marquesas)

- HIMU (St Helena,

Rurutu, Tubuai) ф St Helena [2]

- Azores [3]

$\phi \quad *$ Iceland [3]

\$ *Hawai'i [4]

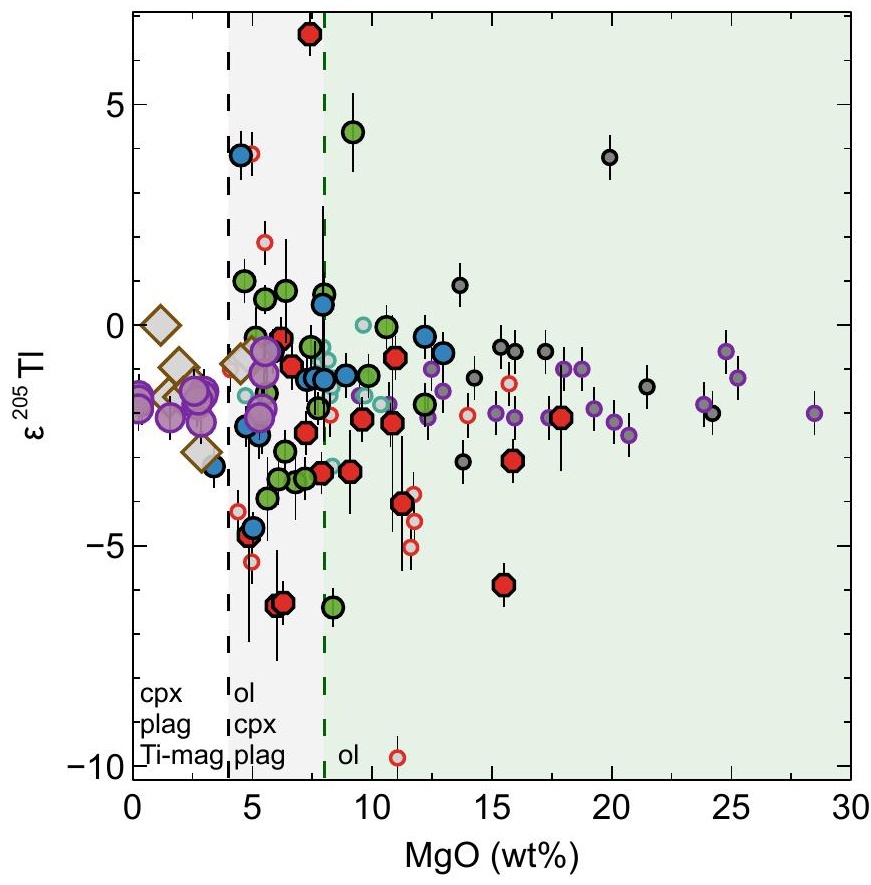




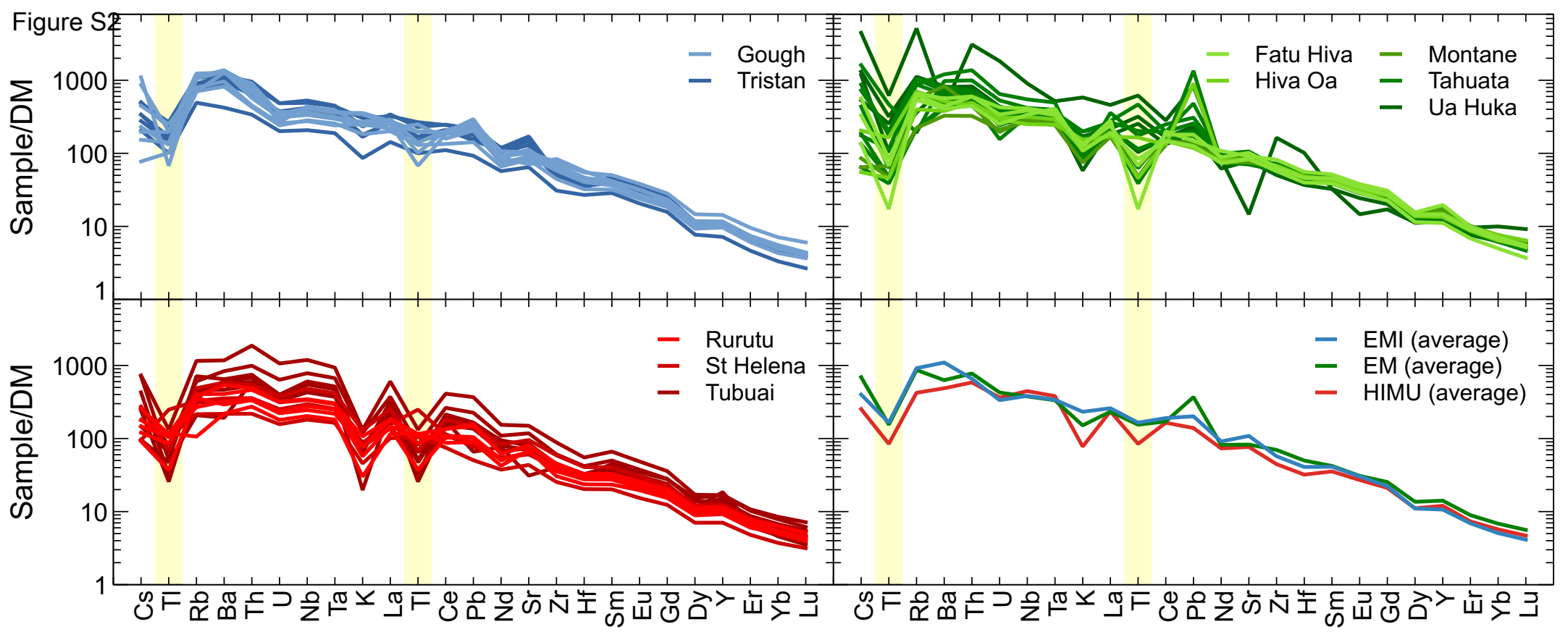




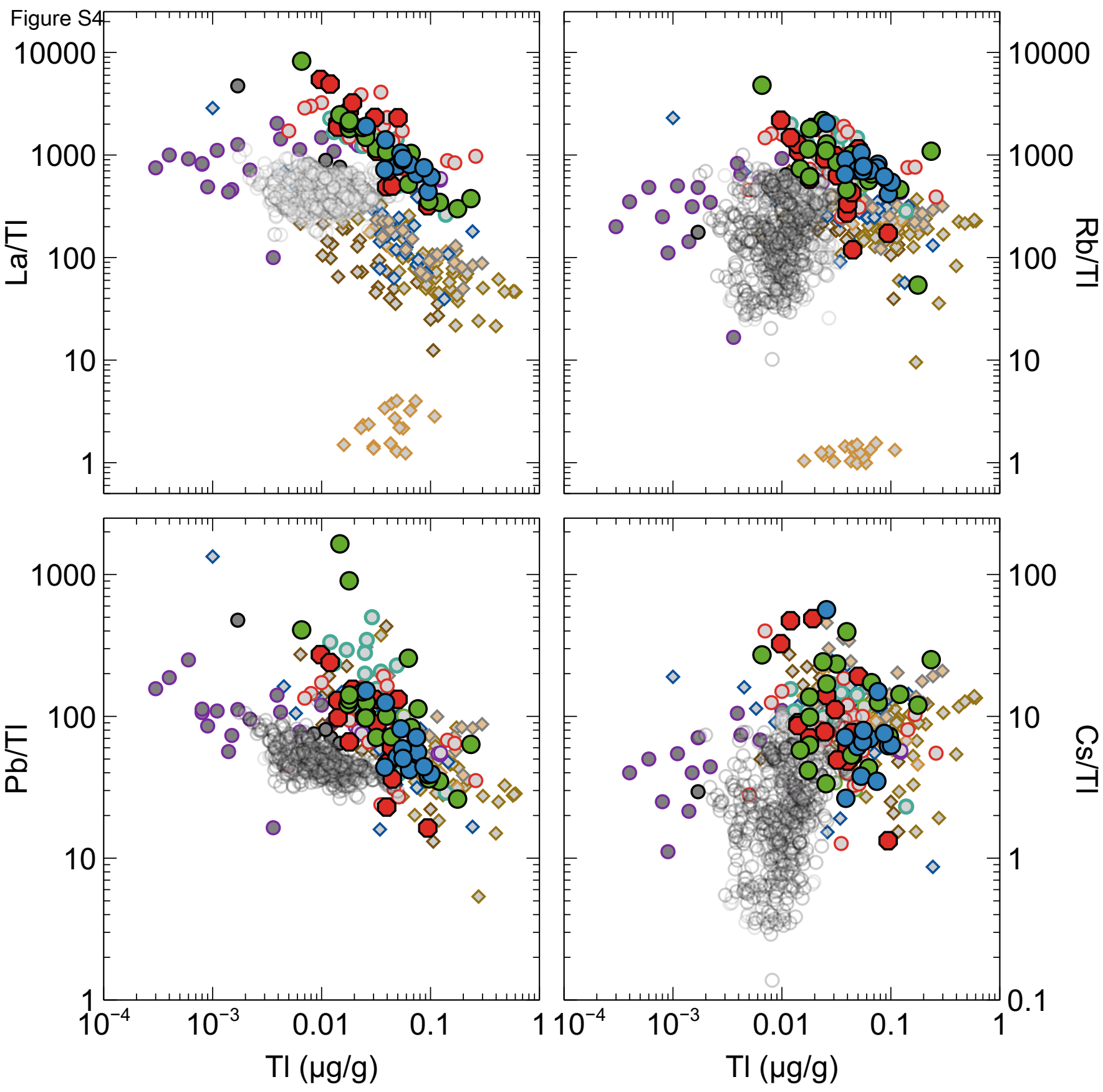




\section{Figure $\$ 55$}

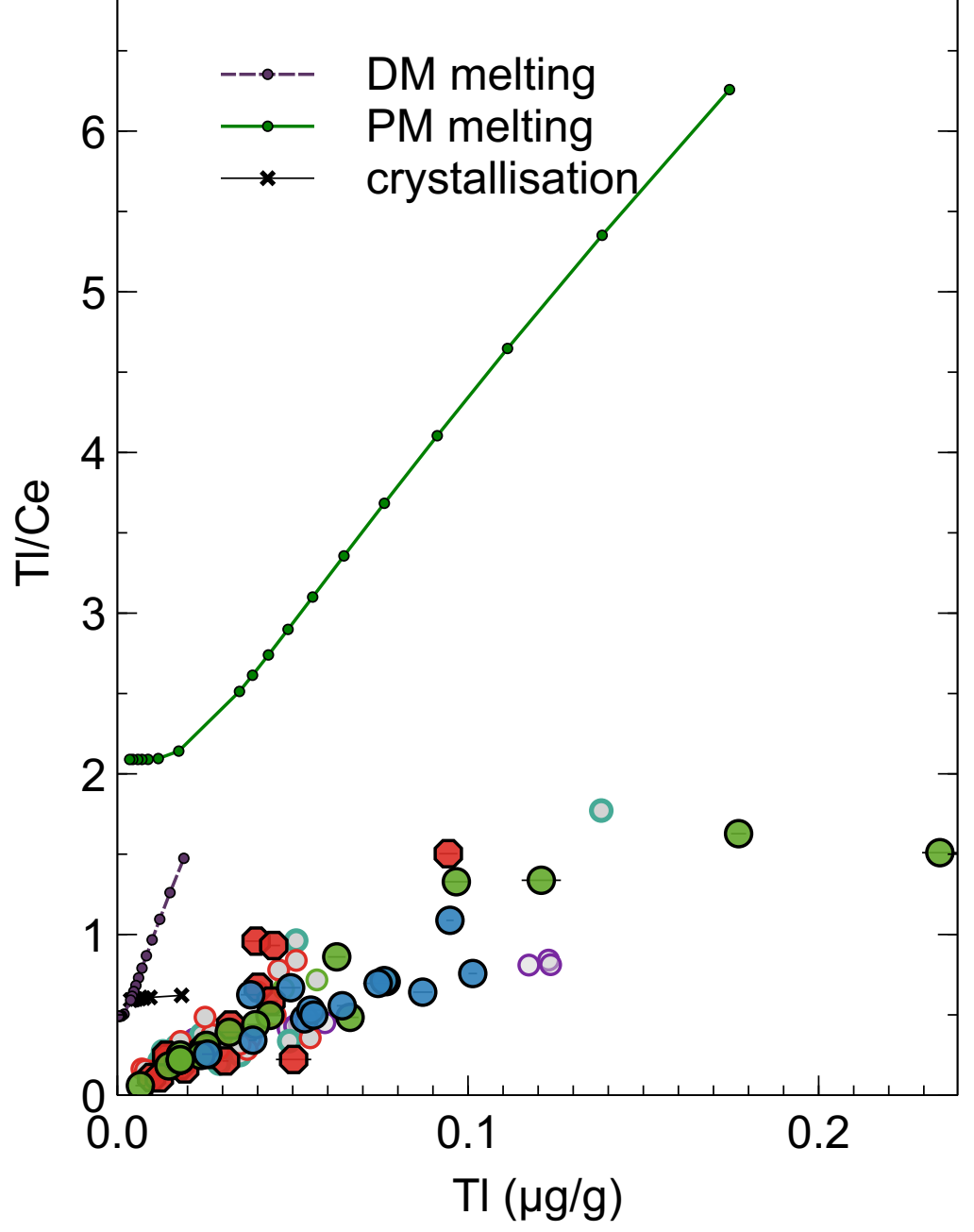


